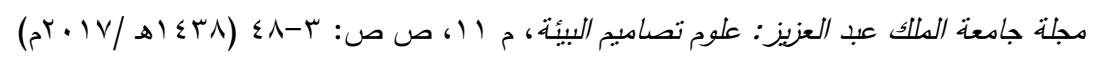

DOI: 10.4197 / Env.11-1

\title{
المراصد الحضرية دراسة مقارنة لتجربة المملكة العربية السعودية مع تجارب الدول الأخرى "التحديات وسبل التطوير"
}

أمير محمد العلوان

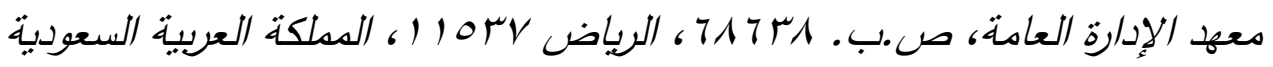
ameeralalwan@yahoo.com

المستخلص. يهدف هذا البحث إلى التعرف على تجربة المراصد الحضرية في المملكة العربية

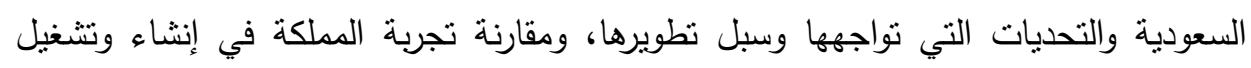

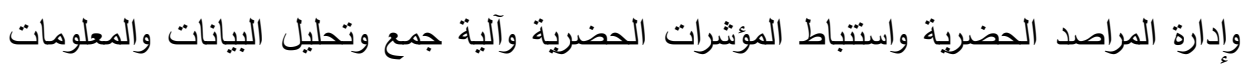

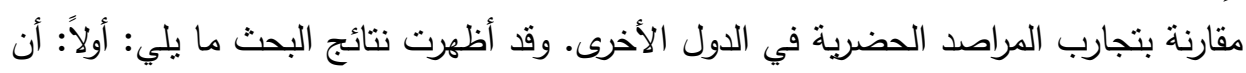

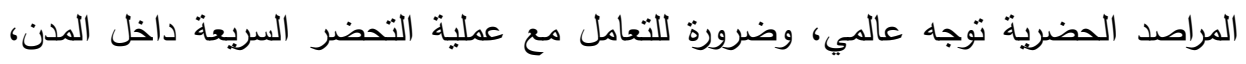

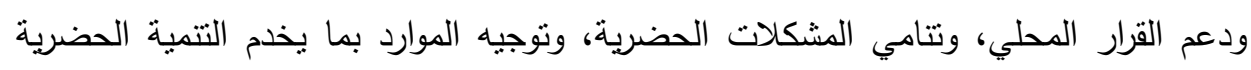

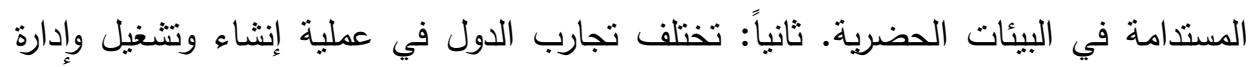

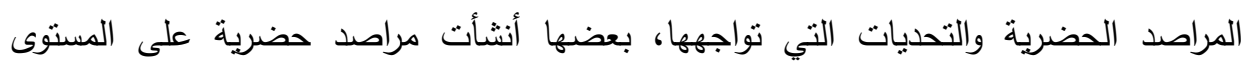

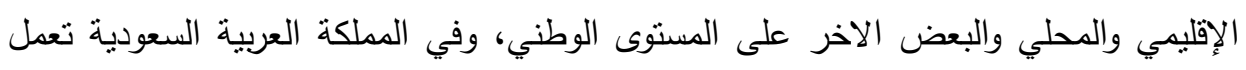

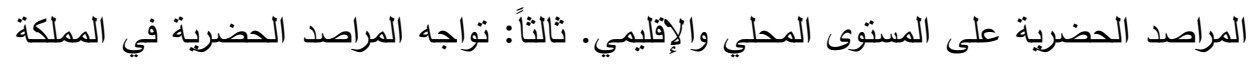

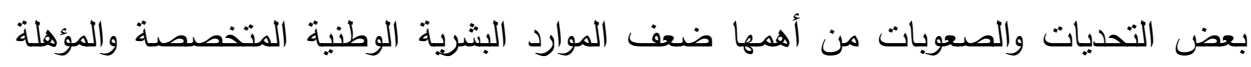

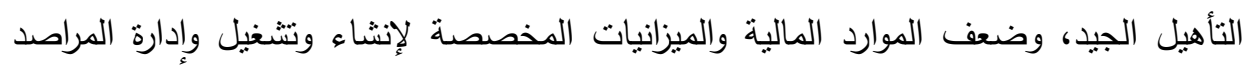

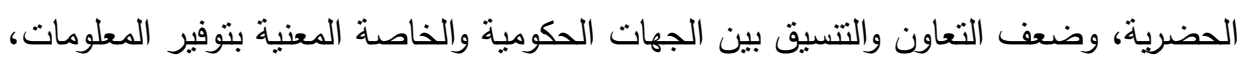

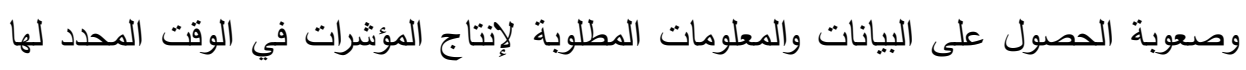

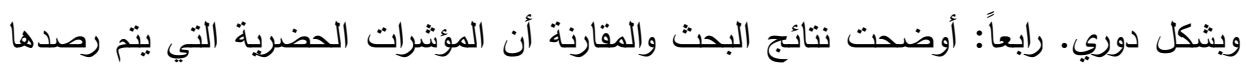

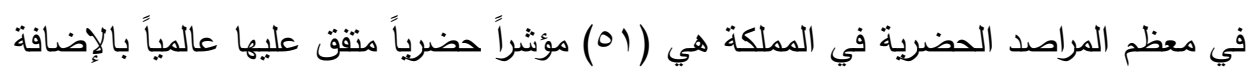

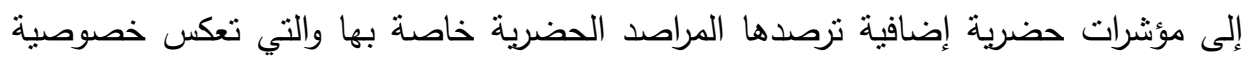

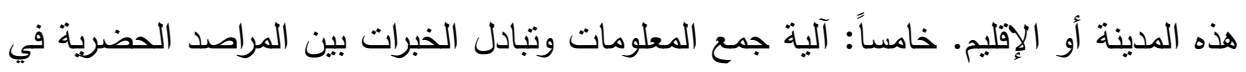




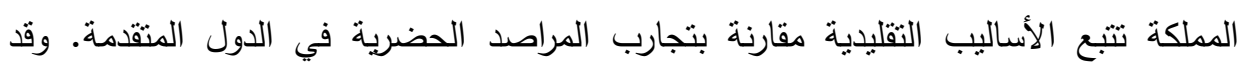

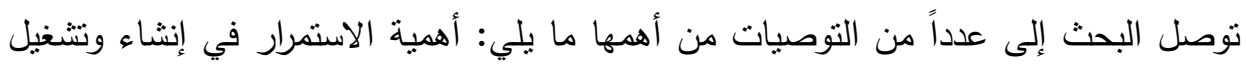
المراصد الحضرية في المملكة وبالأخص في المدن المتوسطة والصغيرة ودعمها بالموارد البشرية الصناء الوطنية المتخصصة والمؤهلة، وتوفير الموارد المالية والميزانيات المطلوبة لها، وتوظيف التقنيات

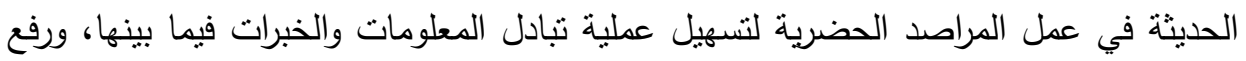
مستوى اهتمام المسئولين المعنين بضرورة المراصد الحضرية في عملية دعم القرار المحلي

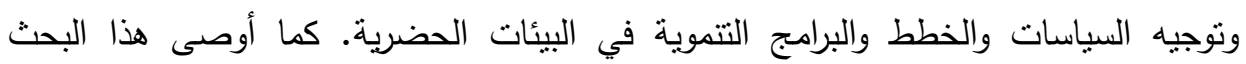

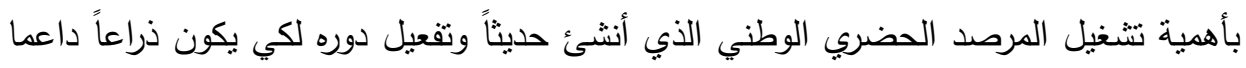
ومساند للمراصد الحضرية المحلية والإقليمية في المملكة. كلمات مفتاحية: المراصد الحضرية، المؤشرات الحضرية، برنامج الأمم المتحدة للمستوطنات

$$
\text { البشرية (الموئل). }
$$

الحيز الحضري للمدن، وبطبيعة مراحل النمو التي

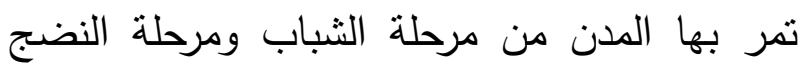
إلى مرحلة الثيخوخة، ويمكن أن تتجدد في عملية

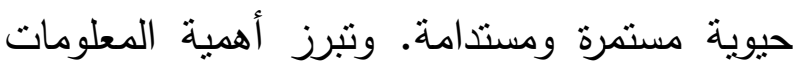
والبيانات والمؤشرات الحضرية الدقيقة في أوقات وأماكن محددة حيث بدونها لان لانئ يمكن إعداد إستراتيجيات وسياسات وبرامج ومشاريع تتموية ومن لامن لهن ثم لا يمكن إدارة ومتابعة وتقويم العملية الحضرية.

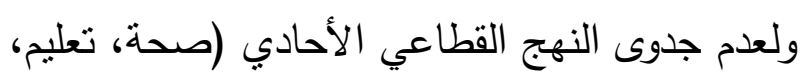
تجارة، صناعة ... إلخ) في تحقيق التنمية الحضرية، أصبح من الضروري إيجاد منهجية تأخذ الحيز المكاني مدينة أو محافظة أو منطقة كوحدة الجنرة

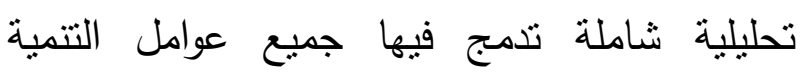
القطاعية. لذا عند إنشاء مركز الأمم المتحدة فئة فئه للمستوطنات البشرية في عام 979 ام كان من الاهن

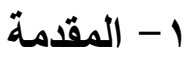

عرفت عملية الرصد والإحصاءات وعمل المؤشرات

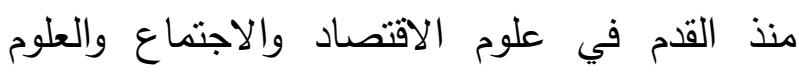
التطبيقية وتم الاهتمام بها على المستويات القطاعية، تجارة، صناعة، عمران، بيئة، زراعة، خدمات، بنية تحنية، صحة، تعليم، مرافق وخدمات .... إلخ.

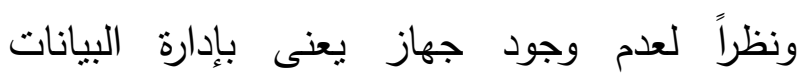

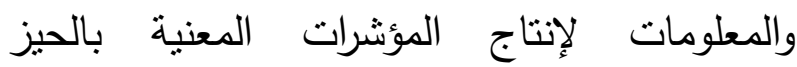
المكاني، فقد نشأت فكرة المراصد الحضرية ونظم المؤشرات الحضرية لتفي بإعداد السياسات الحضرية ونظم الإدارة المحلية من تتفيذ ومتابعة وتقييم وتقويم

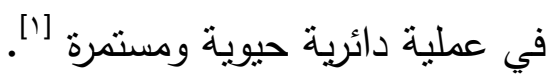
ولفهم المرصد الحضري ورسالته لابد من فهم

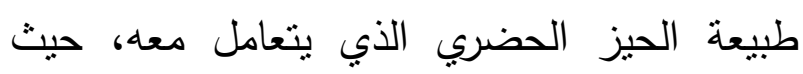

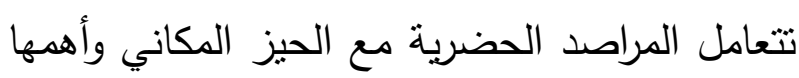


وبسعى هذا البحث إلى التعرف على واقع

المراصد الحضرية في المملكة العربية السعودية والتحديات التي تواجهها وسبل تطويرها ومقارنتها ببعض التجارب العربية والعالمية. ويشتمل هذا البحث على خمسة أجزاء: الجزء الأول يتتاول الإطار العام للبحث ويشمل مشكلة وأهداف وتشاؤلات وأهمية ومنهجية البحث، ويتتاول الجزء الثاني مفهوم المراصد الحضرية، وأهميتها، وأهدافها، ومستوياتها .... إلخ، ومفهوم المؤشرات الحضرية، والغرض منها، وكيفية تحديديها، وتصنيفها، وتطورها، .... إلخ، أما الجزء الثالث فيتناول الوضع الراهن للمراصد الحضرية في المملكة العربية السعودية والمعوقات والتحديات التي تواجهها، ويتناول الجزء الرابع عقد مقارنة بين تجربة المملكة في إنشاء وتشغيل وإدارة المراصد الحضرية والمؤشرات الحضرية وآلية جمع البيانات والمعلومات وتحليلها مقارنة بتجارب الدول الأخرى، وأخيراً يستعرض الجزء الخامس أبرز النتائج والتوصيات.

$$
\text { r - الإطار العام للبحث }
$$

r - r - r مشكلة البحث

تزداد أهمية البيانات والمعلومات للمجتمعات البشرية يوماً بعد يوماً ، خاصة أن نلاك المجتمعات تتجه أكثز لتصبح مجتمعات حضرية تسهم معلوماتها الدقيقة في تحديد وتقييم مستويات التتمية الحضرية، وهو ما يساعد صناع القرار على اتخاذ القرار المناسب
ضمن أهدافه الرئيسية العناية بمسار عملية التحضر المتتامية عالمياً [؟] ولتحقيق التتمية الحضرية المستدامة ومتابعة عملية التحضر بدأت العديد من المدن والمحافظات والأقاليم في كثير من الدول المتقدمة بإنشاء بعض بله المراصد الحضرية في أغلبها بدعم ومساندة من المرصد الحضري العالمي التابع لبرنامج الأمم المتحدة للمستوطنات البشرية (UN HABITAT) بنيروبي - كينيا، وكذلك بالتسيق وإشراف من بعض المؤسسات البحثية والأكاديمية ومؤسسات المجتمع المدني المحلية[] أما الدول العربية ومن ضمنها المملكة العربية السعودية فقد بدأت حديثاً بإنشاء ونتخيل بعض المراصد الحضرية في بعض المدن والأقاليم، وقد أولت جامعة الدول العربية موضوع إنشاء المراصد الحضرية للدول العربية أهمية كبيرة، وهو ما يقتضي إنشاء شبكة من المراصد الحضرية الوطنية والمحلية بكل دولة عربية، كما عملت الجامعة وبالتسيق مع المؤسسات الإقليمية لبرنامج الأمم المتحدة للمستوطنات البشرية (UN HABITAT) على تشجيع ودعم الدول العربية ومدنها بل والجهات المعنية بالتتمية الحضرية على إنتاج المؤشرات الحضرية لكي تصبح أداة أساسية لصناع القرار في رسم السياسات و وإعداد الخطط لتحقيق التتمية الحضربة المستدامة. 
كما أن بعضاً منها بعاني من تدني الميزانيات والموارد المالية المخصصة، وضعف نطبيق وتوفير التقنيات الحديثة المطلوبة لعمل المراصد الحضرية

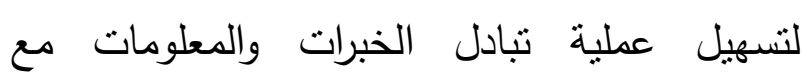
المراصد الحضرية العالمية الأخرى من خلال شبكات

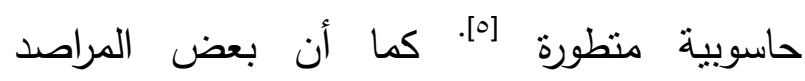

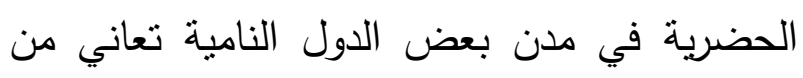

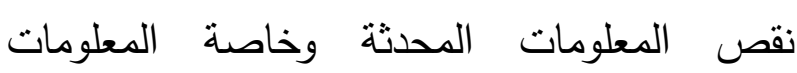
التفصيلية على المستوى المحلي عن بعض الظواهر

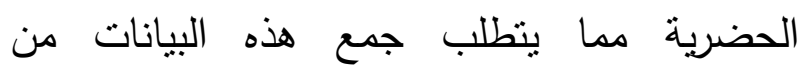
مصادرها الأولية وما ينطلبه ذلك من تكلفة عالية

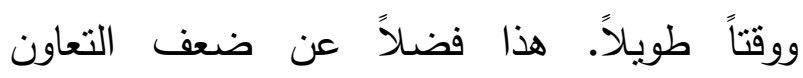
والتسيق من بعض الجهات الحكومية والخاصة المعنية بتوفير المعلومات المطلوبة وفي الوقت الحدد لها وبثكل دوري لكي ينم الخروج بالمؤشرات

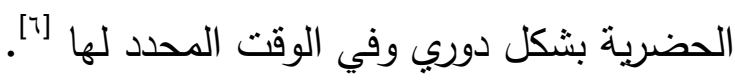
وتعد المملكة العربية السعودية من أوائل الدول

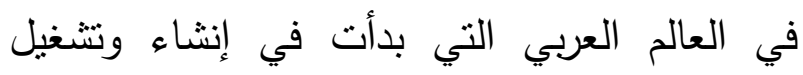

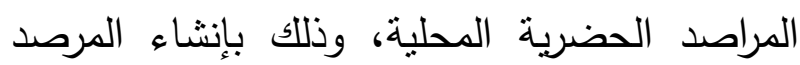
الحضري بأمانة منطقة الددينة المنورة في عام r آب (هـ، ومنذ ذلك الوقت والعمل جارِ على إنثاء

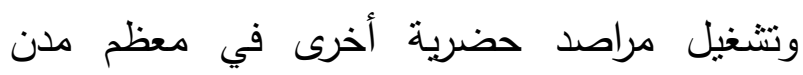
ومناطق الملكة الثلاث عشرة، ومرصد حضري في في في محافظة جدة والأحساء والطائف وحفر الباطن، إضافة إلى مرصد حضري وطني ومقره الرياض [ل]
بشأنها، ويتم إعداد سياسات التتمية ومثابعتها بناء على نقي أدلة يعبر عنها بمؤشرات رقمية كمية أو نوعية عن

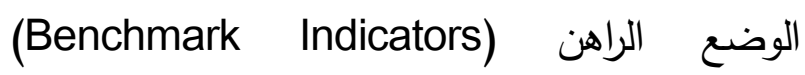
ومؤشرات الأهداف المراد تحقيقها (Goal Indictors) Policy ) والخيارات المتاحة لنطبيق نلاك السياسات (Options Indictors ومؤشرات متابعة (Cost Benefit Indicators) Performance ) النقام نحو تحقيق الأهداف Measurement Indicators المراصد الحضرية من خلا مركز الأمم الدتحدة

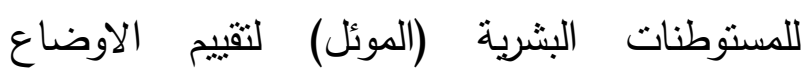
واتجاهات النحضر العالمي [4]. وعلى الرغم من أهمية البيانات والمعلومات في قياس أداء ودعم القرار للبيئات الحضرية وخاصة البانية

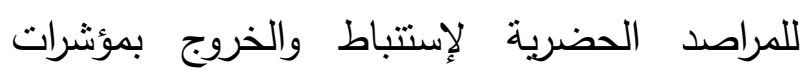
حضرية نساعد متخذ القرار في توجيه السياسات والخطط والبرامج لتحقيق التتمية الحضرية المستدامة فئاع للددن، إلا أن بعض الدراسات الحديثة نتثير إلى الى الفي بعض التحديات والدعوقات الني تواجهها المراصد التدات الحضرية في الكثير من الددن في الدول النامية أو

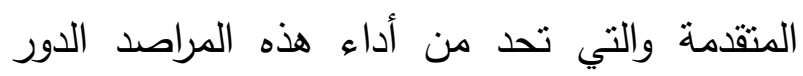
الدناط بها وبالثكل المطلوب. ولقد أوضحت بعض المض الهراء الدراسات الحديثة أن بعضاً من المراصد الحضرية

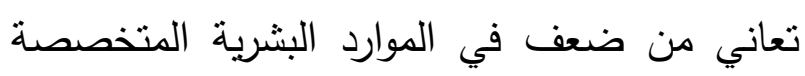
والمؤهلة التأهيل الجيد للقيام بالمهام المطلوب منها، 
يسعى من خلال تحليل تجارب هذه المراصد في عملية الرصد وطرق جمع وتحليل البيانات والمعلومات واستتباط المؤشرات الحضرية وأخذ العبر منها في سبيل تطوير وتحسين عمل المراصد الحضرية في المملكة العربية السعودية.

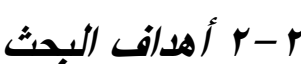

يهدف هذا البحث إلى التعرف على تجربة المراصد الحضرية والمؤشرات الحضرية في المملكة العربية السعودية والتحديات التي تواجهها وسبل تطويرها، وعقد مقارنة بين تجربة المملكة في إنشاء وتتغيل وإدارة المراصد الحضرية والمؤشرات الحضرية وآلية جمع البيانات والمعلومات وتحليلها مقارنة بتجارب الدول الأخرى من خلال ما يلي: 1- 1 - تشخيص التحديات والمعوقات التي نواجه إنثاء وتتشيل وإدارة المراصد الحضرية في المدن في المملكة العربية السعودية. r- عقد المقارنات بين تجربة المملكة العربية السعودية مع تجارب الدول الأخرى في عملية إنشاء وتتغيل وإدارة المراصد الحضرية واستتباط المؤشرات الحضرية.

ץ- تحديد سبل تحسين وتطوير عمل المراصد الحضرية واستتباط المؤشرات الحضرية في

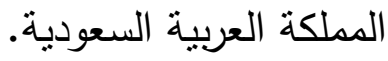

وقد بدأت فعلاً الكثير من أمانات المناطق والبلديات في المدن في المملكة العربية السعودية منذ

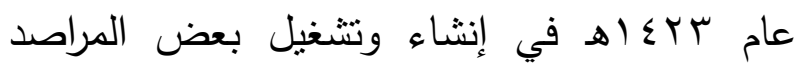
الحضرية من خلال عقود استشارية مدتها سنة ونصف أو سنتان تتجدد تلقائياً منى ما توافرت

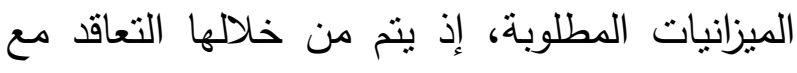
بعض المكاتب الاستشارية المتخصصة في هذا لهاب المجال التي تعمل على دراسة شاملة تشمل جمع

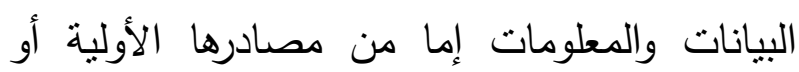
الثانوية وتحليلها وفق منهجية محددة للخروج ببعض الئل المؤشرات الحضرية التي تعكس واقع التتمية الحضرية في المدينة أو المنطقة والتحديات التي تواجهها من تحديات عمرانية، تعليمية، وصحية، وبيئية ... الخ وتتشرها في تقارير دورية تقدمها لدى نقيه

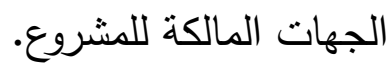
ونظراً لقلة الدراسات المحلية حول موضوع المراصد الحضرية بشكل عام، والتحديات والمعوقات التي تواجه إنثاء وتتغيل وإدارة المراصد الحضرية بشكل خاص. فإن هذا البحث هو محاولة لعمل دراسة تحليلية من خلال عقد مقارنة لتجربة بعض لهض المدن في المملكة العربية السعودية في إنشاء وتتغيل وإدارة المراصد الحضرية بتجارب بعض المدن في بعض الدول العربية والعالمية المختارة والتي لها تجربة كبيرة في مجال الرصد الحضري واستتباط المؤشرات الحضرية. كما أن هذا البحث 
محاولة لطرح بعض المقترحات والتوصيات لتحسين وتطوير عمل المراصد الحضرية في المملكة العربية السعودية.

كما تبرز أهمية هذا البحث في سد النقص في الدراسات العلمية النظرية التي تثتاول هذا الموضوع لهيه الحيوي والمهم للتخطبط الحضري بشكل عام وعلاقته بقضايا التتمية والتتمية الحضرية المستدامة بشكل خاص حيث تفتقر الأدبيات المحلية إلى وجود

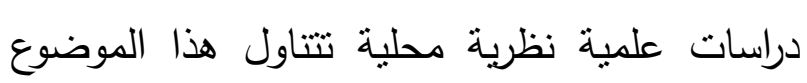
الحيوي وخاصةً الدراسات العلمية الحديثة المتعلقة بالمراصد الحضرية واستتباط المؤشرات الحضرية والتحديات التي نواجهها، وسبل نطويرها، ودورها في دعم القرار التخطيطي المحلي داخل المدن. ونظراً لقلة الدراسات المحلية حول هذا هـات

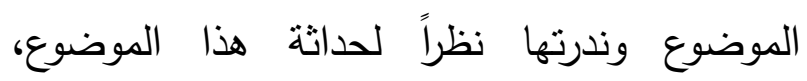

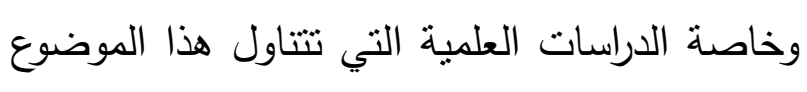
الحيوي والهام للتتمية بشكل عام والتتمية الحضرية بشكل خاص، فإن هذا البحث هو محاولة لتسليط

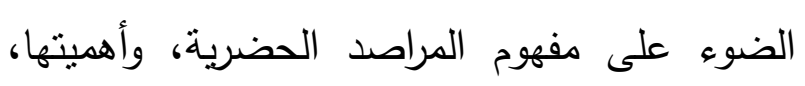

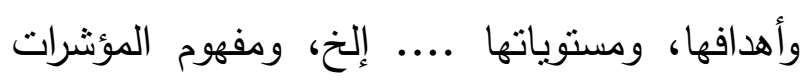

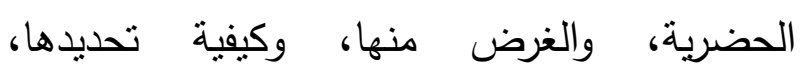
وتصنيفها، وتطورها، ... إلخ، كما ينتاول هذا، وال البحث الوضع الراهن للمراصد الحضرية في المملكة

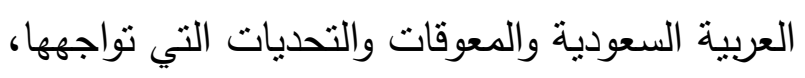
ودراسة وتحليل عينة مختارة من المراصد الحضرية r-r

يتم تحقيق أهداف البحث من خلال الإجابة عن التساؤلات التالية: ا- ما واقع المراصد الحضرية في المملكة العربية السعودية؟ r- ما التحديات التي تواجه المراصد الحضرية في المدن في المملكة العربية السعودية؟ r- ما تجربة المملكة مقارنة بتجارب الدول

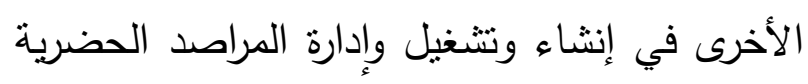
وإسنتباط المؤشرات الحضرية؟ ع- ما سبل تحسين وتطوير المراصد الحضرية في المملكة العربية السعودية؟

$$
\text { r - أهمية البحث }
$$

تكمن أهمية هذا البحث في أن الكثير من المراصد الحضرية في المملكة العربية السعودية تواجه العديد من التحديات والمعوقات، من أبرزها

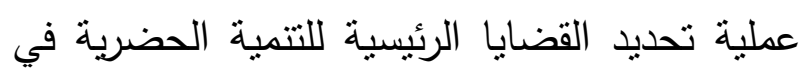
المدينة، ومن ثم اسنتباط المؤشرات الحضرية المناسبة لها، وآلية جمع والحصول على البيانات والمعلومات الضرورية لها، وتحليلها وفق منهجية ولهية

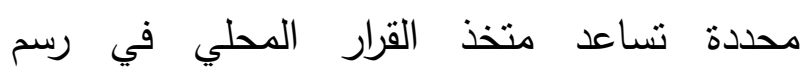
السياسات، ووضع الخطط، وتحديد الأولويات التتموية في البيئات الحضرية وذلك لتحقيق التتمية الحضرية المستدامة، ومن ثم فإن هذا البحث هو 
المحلية، وأخيراً عقد مقارنة بين تجربة المملكة في مفهوم المراصد الحضرية، وأهميتها، وأهدافها، إنشاء ونشغيل وإدارة المراصد الحضرية والمؤشرات ومستوياتها ... إخ، وكذلك مفهوم المؤشرات الحضرية وآلية جمع وتحليل البيانات والمعلومات الحضرية، والغرض منها، وكيفية تحديدها، مقارنة بتجارب بعض المراصد الحضرية في الدول وتصنيفها، وتطورها، .... إلخ. ب- 1 مفهوم المرصد الحضري الأخرى.

يوجد هناك أكثر من مفهوم وتعريف للمرصد r - r منهجية البحث الحضري من أهمها تعريف برنامج الأمم المتحدة للمستوطنات البشرية (UN HABITAT)، إذ عرف بـ المرصد الحضري على أنه عبارة عن شبكة محلية تجمع أصحاب المصالح المشتركة والمعنية بجمع وتحليل ونشر البيانات والمعلومات ووضعها على شكل مؤثرات تعكس القضايا التي تهم المجتمع ولها الأولوية في مجال التتمية المستدامة. ويمكن استخدام هذه البيانات والمعلومات التي تم جمعها بهدف دعم عملية صنع القرار، وصياغة السياسات والإستراتيجيات الفاعلة، ولذا يعد المرصد الحضري جهازاً يعنى بمتابعة ورصد التتمية الحضرية على المستوبين المحلي والوطني [9]

كما يعرف البعض المرصد الحضري على أنه عبارة عن مركز متخصص يعمل على جمع وتحليل المؤشرات الحضرية التي تسهم في إعداد سياسات التتمية الحضرية على جميع المستويات ومتابعة تقييمها للتغلب على النواحي السلبية وتطوير النواحي الإيجابية، وهو جهاز استشاري لمعدي سياسات التتمية الحضرية [•"]

انطلاقاً من طبيعة موضوع البحث والأهداف التي بسعى إلى تحقيقها، فقد تم استخدام المنهج الوصفي المقارن الذي يعتمد على المقارنة في دراسة الظاهرة وبيرز أوجه الثبه والاختلاف فيما بين ظاهرتين أو أكثر، وبعتمد الباحث دن خلال ذلك على مجموعة من الخطوات من أجل الوصول إلى الحقيقة العلمية المتعلقة بالظاهرة المدروسة. وقد قام الباحث باستخدام هذا المنهج الذي يقوم على وصف وتحليل للوضع الراهن للمراصد الحضرية في المدن في المملكة العربية السعودية، وحالة الثبة أو الاختلاف القائمة بينها وبين تجارب الدول الأخرى في مجال إنشاء ونتشيل وإدارة المراصد الحضرية والمؤشرات الحضرية وآلية جمع البيانات والمعلومات والاستفادة منها في تطوير

$$
\text { وتحسين عمل المراصد الحضرية[^]. }
$$

يتضمن هذا الجزء من البحث استعراضاً للإطار النظري الذي انطلق من البحث إذ يتتاول 


\section{r-r نبذة تاريخية عن تطور المراصد الحضرية}

في البداية أنثأ البنك الدولي ومركز الأمم

المتحدة للمسنوطنات البشرية (UN HABITAT) عام 919 ام برنامج مؤشرات قطاع المأوى لتفعيل

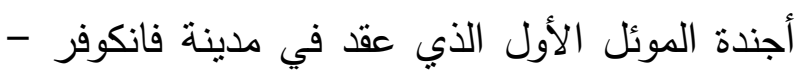
بكندا عام (9V7 ام)، لكي يمكن المؤس الكونسات الحكومية من إدارة قطاع الإسكان وتوفير المعلومات المكات

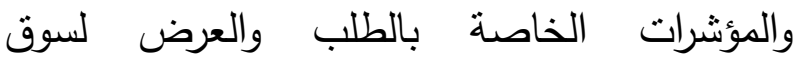
الإسكان. تلا ذلك أثناء العملية التحضيرية في عام

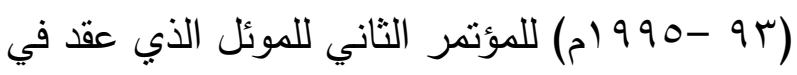
مدينة إسطنبول بتركيا عام 999 ام تم تطوير مفهوم (مؤشرات قطاع الإسكان) إلى مفهوم أثنمل وهو النهان (المؤشرات الحضرية) لتضم بجانب قطاع الإنكان إلى العان كل العوامل المتعلقة به والدتقاطعة معه من بيئة وسكان ونقل وبنية تحتية وخدمات ومرافق وتتمية اقتصادية واجتماعية المعنية بالحيز الجغرافي الحضري العمراني على كافة المستويات الإدارية. بعد ذلك أنثأ مركز الأمم المتحدة للمسنوطنات

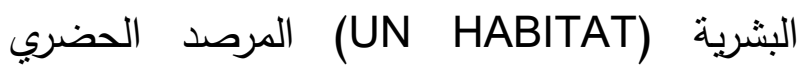
العالمي في نيروبي -ككينيا عام 994 ام ليقوم بمساعدة الدول والحكومات المحلية على إنثاء

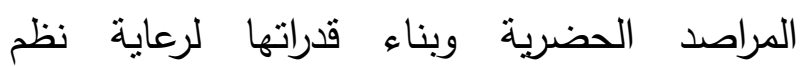

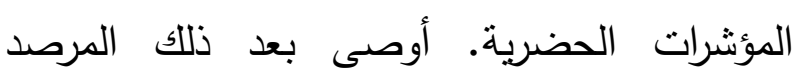
الحضري العالمي بمركز الأمم المتحدة للمستوطنات البشرية بنطوير مؤشرات حضرية بكل دولة ومنطقة الأنة
ويرى البعض المرصد الحضري هو عبارة عن مركز متخصص بأخذ شكل إدارة متخصصة تنشأ في صلب الهيكل التنظيمي لإدارة الدينة. تقوم هذه الإدارة الفنية بعمليات جمع وتحليل البيانات والإحصاءات والمعلومات في مجال التتمية الحضرية المختلفة، وتثنيلها ومعالجتها لتنتشي مع منطلبات

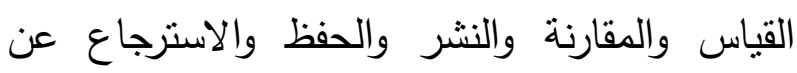
مجالات تتمية المدينة بهدف العمل على تحسين ظروف الحياة لسكان الدينة. أي تقوم هذه الوحدة

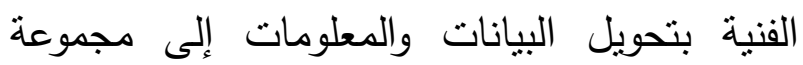
مؤشرات تساعد صناع القرار السئولين عن التتمية الحضرية في وضع السياسات ورسم الخطط التي تحقق أهداف تتمية الدينة وسكانها سواء التتمية العمرانية أو الاقتصادية أو الاجتماعية أو البيئية، أي

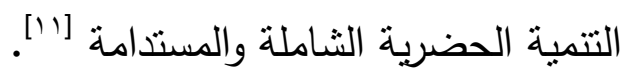
كما يعرف المرصد الحضري على أنه عبارة عن جهاز إداري متخصص ذي شخصية اعتبارية مستقلة، يشارك في فعاليته الجهات الحكومية ومنظمات المجتمع المدني والقطاع الخاص، ويعمل هذا الجهاز على إنتاج وتحليل المؤشرات الحضرية التي تسهم في إعداد سياسات التتمية الحضرية ومتابعتها وتقيمها ومن ثم تقويمها بشكل دوري ومستمر في إطار ما يعرف بالتخطيط المستمر [بrا]. 
أنتجته المدن والدول من مؤشرات في عام 997 ام

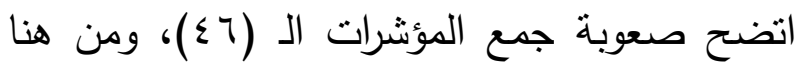
ابتكر تلخيص أجندة الموئل في (·r) محوراً يعبر

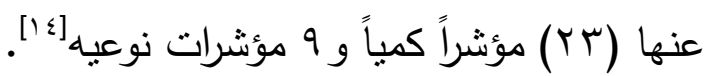
بعد ذللك بدأ الكثير من المدن حول العالم في إنشاء مراصد حضرية خاصة بها، ولقد قام المرصد

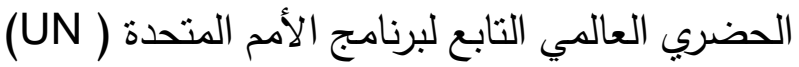

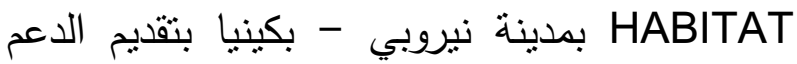

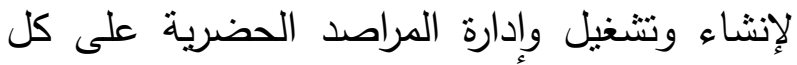
المستويات المحلية والاقليمية والوطنية وبالتحديد التركيز على المراصد المحلية بالمدن، بالإضافة إلى ولى عملية ربط هذه المراصد بشبكة الربط العالمية وتبادل أفضل الخبرات والممارسات العالمية في هذا المجال.

\section{ب- - م أهمبية المرصد الحضري}

تكمن أهمية المرصد الحضري في أنه وسيلة

داعمة لإدارة التتمية الحضرية في المجتمع والتنبؤ بنتائج برامج التتمية في البيئة الحضرية. كما تبرز أهمية المرصد الحضري في اعتماده على جمع البيانات والمعلومات الحضرية وتحليلها والخروج بمؤشرات متعلقة بقضايا التنمية العمرانية، والتتمية الاجتماعية، والتتمية الاقتصادية، والبيئة، وقضايا

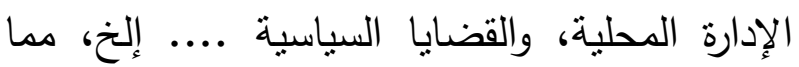
يسهم في توجيه السياسات والخطط والبرامج التتموية التوجيه الصحيح، ويدعم اتخاذ القرارات السليمة[ب']
ومدينة لتعكس الخصوصيات الوطنية والإقليمية والمحلية بالإضافة لمجموعة من المؤشرات الأساسية، كأدوات لإعداد قاعدة مؤشرات حضرية ومتابعة وتتفيذ وتقييم سياسات التنمية الحضرية على هردي جميع المستويات. وذللك لتفعيل أجندة الموئل الأول وتمكين الجهات الحكومية ذات الصلة من إدارة قطاع الإسكان وتوفير المؤشرات المتصلة بالطلب والعرض لسوق الإسكان بهدف تمكين القطاع

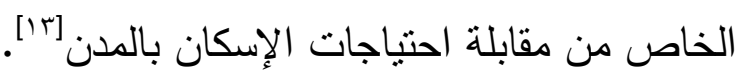
وللتحضير للموئل الثاني الذي عقد في مدينة إسطنبول - بتركيا عام 997 ام اتضح أن قطاع الإسكان وحده لا يعكس عملية التحضر بشكلها الثامل ولا يمكن تطويره بمعزل عن بقية القطاعات والعوامل المتعلقة به والمؤثرة فيه من سكان وبيئة

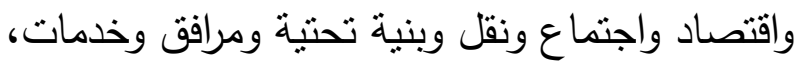
ولذلك نم تطوير مؤشرات قطاع الاسكان لتصبح المؤشرات الحضرية. وفي عام 990 ام أنتج أول دليل للمؤشرات الأساسية بواسطة مركز الأمم المتحدة للمستوطنات البشرية (UN HABITAT) وبه (7٪) مؤشراً حضرياً يعكس أهم القواسم المشتركة للتحضر على جميع المستويات، وفي عام 999 ام أضيفت لها خمس مؤشرات حضرية ليتضمن إطار المؤشرات القواسم المشتركة عالمياً في دليل التتمية البشرية ومؤشرات لقياس فعالية المجتمع المدني. وللتحضير للموئل الثاني +o ولتقييم ما 
إقليم أو منطقة جغرافية محددة، والمرصد الحضري المحلي على مستوى المدينة. ويعد المرصد الحضري العالمي بنيروبي - بكينيا التابع لبرنامج الأمح المتحدة للمستوطنات البشرية هو الجهاز الرئيس الذي ترتبط به جميع المراصد الحضرية من خلال شبكة المراصد العالمية. وتعمل المراصد بجميع مستوياتها في مجالات جمع وإدارة وتحليل البيانات والمعلومات ومن ثم إنتاج المؤشرات الحضرية على المستوى المختص به المرصد. وتسهم مخرجات الرصد الحضري والمؤشرات الحضرية في رسم السياسات والإستراتيجيات والخطط للتنمية العمرانية والتتمية الثاملة والمستدامة. ويتم ذللك بعد التحليل العلمي والمنهجي للمشكلات والتحديات التي تواجه التتمية سواءً كان ذلك على مستوى المدينة أو الإقليم أو الدولة. وتبدأ المستويات المختلفة للمراصد الحضرية من المستوى المحلي مستوى المدينة التي تمنل المنصات المحلية للسياسات على مستوى المدن بالتسيق مع المراصد الحضرية الوطنية، ثم المراصد الوطنية المرتبطة بشبكة من المراصد المحلية للتسيق، وبناء القدرات، والدعم في جمع وتحليل البيانات و والمعلومات لوضع السياسات التتموية على المستوى الوطني، ثم الإقليمية وهي عبارة عن مراصد حضرية بين الدول في الإقليم التي نشترك في منطقة جغرافية معينة، أو لديها عوامل اقتصادية، أو ثقافية أو إجتماعية مشتركة، ثم مثن
ب- أهداف المراصد الحضرية

تهدف المراصد الحضرية إلى تحقيق عدد من الأهداف للوصول التتمية المستدامة في البيئة الحضرية، ويمكن تلخيص أهم أهداف المراصد الحضرية فيما يلي: أولاً: إعداد إطار للمؤشرات الحضرية على المستوى المحلي، ثانياً: تفعيل عملية الثراكة بين القطاع الحكومي والقطاع الخاص والمجتمع المدني في إعداد إطار المؤشرات الحضرية، ثالثاً: تأسيس وتطوير وتتفيذ قاعدة بيانات على المستوى المحلي، رابعاً: القيام بعملية تحليل المؤشرات الحضرية لتشخيص الوضع الراهن للبيئة الحضرية، خامساً: استخدام حزمة المؤشرات في متابعة وتقييم سياسات التتمية الحضرية، سادساً: التحليل والمقارنة بين المناطق والمدن لدعم متخذ القرار في تحقيق التتمية المتوازنة، سابعاً: رصد الأوضاع الحضرية ودعم صناعة القرار في شئون التتمية الحضرية بالمعلومات على المستوى الوطني والإقليمي والمحلي، ثامناً: تتسيق العمل فيما بين المراصد المحلية والربط فيما بينها عن طريق المواقع الإلكترونية، تاسعاً: تبادل أفضل ممارسات التتمية الحضرية على جميع المستوبات]["] ب-ه مستويات المراصد الحضربية يوجد هناك عدة مستويات من المراصد الحضرية، إذ يوجد المرصد الحضري الوطني على مستوى الدولة كوحدة واحدة، والإقليمي على مستوى 
يستخرج منها مؤشرات ومقاييس، ويمكن تجميع بعض هذه المؤشرات لاستخراج دليل محدد مثال ذلك هونس

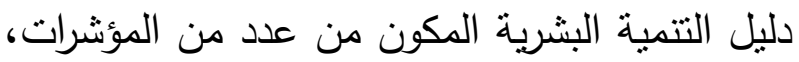
وهذا يمثل قمة هرم المعلومات [ب"]

كما تعد المؤشرات الحضرية - من جهة -

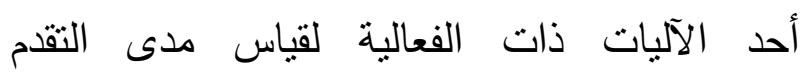
المستهذف للمستقرات الحضرية بمستوياتها المختلفة لتحقيق النتائج المنشودة للتنمية المستخامة، ومن جهة أخرى فإن هذه المؤشرات الحضرية تمثل في مجملها أرضية صلبة وواقعية لعملية اتخاذ القرار التتموي هلئي

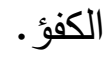

فأما من حيث فعالية هذه المؤشرات في القياس التتموي فإنها تقدم تصور معياري رقمي يمكن حسابه ودمجه في معادلات ومقارنته بالمدن أو بالدول الأخرى دورياً بحيث يعطي صورة واضحة عن حالة التتمية، وأما من حيث كفاءته في عملية بحتية اتخاذ القرار فإنه يمكن من خلالها منابعة التغيرات الدورية الواقعية نحو التقام أو التراجع في تحقيق

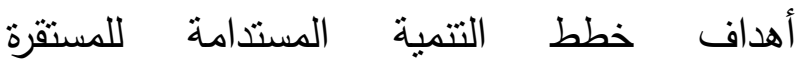

$$
\text { الحضرية:[1 [i]. }
$$

\section{V- تطور المؤشبات الحضرية}

بدأ الاهتمام عالمياً بتطوير مؤشرات في

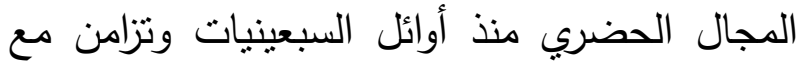
الفترة التي أدرك فيها المجتمع الدولي تحديات الزيادة
المرصد الحضري العالمي الذي يمثل المنصة الرئيسية لكل المراصد الحضرية ويساعد جميع لهريد الثركاء في عملية الإثراف وتقييم التوجهات الحضرية العالمية وقياس التقدم في تحقيق من خلال شبكة (UNHABITAT AGENDA) عالمية تربط كل هذه المراصد مع بعضها

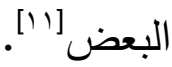
با -7 مفهوم المؤشر الحضري يعد المؤشر مقياساً يلخص معلومة تعبر عن ظاهرة أو مشكلة معينة، وهو يجيب عن أسئلة محددة يستفسر عنها صانع القرار. والمؤشر يوفر معلومة كمية أو نوعية تساعد في تحديد أولويات التتمية الحضرية، وهو أساس لوضع الونع السياسات واعداد خطط تحقيق أهداف تحسين جودة حياة

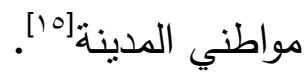
ويأخذ قطاع المعلومات الذي تبني عليه وتستخرج منه المؤشرات الثكل الهرمي، حيث يتكون من قاعدة عريضة من البيانات الخام التي تجمع وتتراكم عن مجالات التنمية المختلفة، وفي الدرجة الأعلى من سلم ذلك الهرم تتحول هذه البيانات الخام

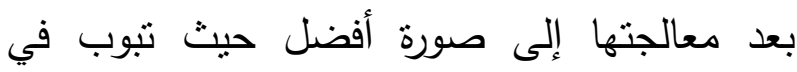
جداول إحصائية ذات أنثال معينة، وتصنف حسب إلى معايير كثيرة تخدم أهداف المستخدم، وبطرق علمية قد تكون استتاجات نظرية أو معادلات رياضية أو الو

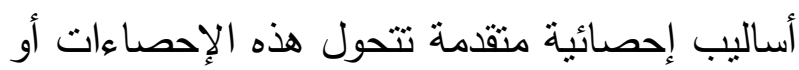


r- برنامج المؤنشرات الحضرية الأول: اشتنمل

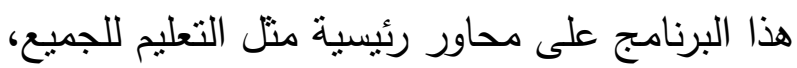

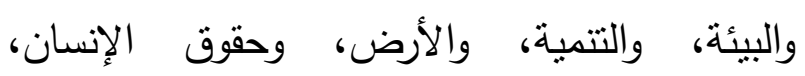

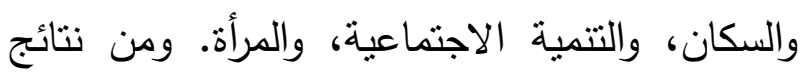
هذا البرنامج والمؤتمرات المرافقة لله تبلور مفهوم التتمية الحضرية والاستدامة وحددت أولويات استدامة المستوطنات البشرية.

r- برنامج المؤشرات الحضرية الثاني: يمثل مؤتمر الموئل الثاني (قمة المدن) الذي عقد بمدينة إسطنبول عام 997 ام نقطة تحول في المجهودات العالمية لدعم المدن المستدامة اجتماعياً وبيئياً. ولقد أقرت الحكومات وشركاؤها في الموئل الثاني بأن العمل لجعل مدن آمنة وصحية ومنصفة يتطلب

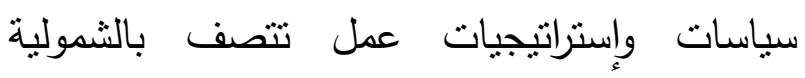
والتتاركية والاحتواء لكل العناصر ذات الصنئ الصلة بالتتمية المستدامة للمستوطنات البشرية. واتسم الموئل الثاني بسابقة تاريخية وهي انضمام ممثلين للسلطات المحلية والمنظمات غير الحكومية والقطاع الخاص وأكاديميين وممثلين لهموعات أخرى في مداولاته التي أنتجت وثثقته العالمية وتسمى أجندة الموئل. وتعد أجندة الموئل خريطة طريق توضح

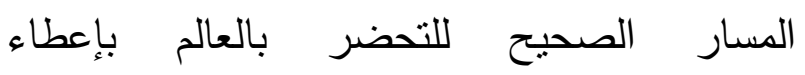
إستراتيجيات ومناهج تؤدي لتحقيق استدامة تتمية المناطق الحضرية بالعالم. وباعتماد الدول الأعضاء

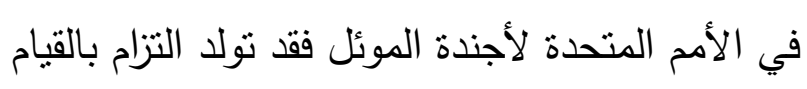

السكانية المتركزة في المدن والبيئات الحضرية، حيث واجه الخبراء في قضايا التحضر في نلايك الفترة حقيقة أن المدن والمراكز الحضرية حتى في بعض فضراء الدول المتقدمة تعاني من نقص في المعلومات الحضرية، كما أنها لا تكفي لإعطاء تصور عن نصن

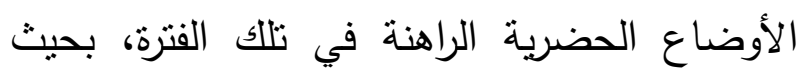
تمكن المعنيين بالثأن الحضري من تحليل هذه اعنه الأوضاع كخطوة أولى قبل وضع المقترحات والحلول للقضايا والمشكلات الحضرية. ولقد سارات مراحل تطوير المؤشرات الحضرية العالمية وفق البرامج التالية: ا- برنامج المؤشرات السكانية: أقرت الأمم المتحدة في عام 911 ام الإستراتيجية العالمية للمأوى والتي أوصت بأن تتبنى السياسيات الحكومية في قطاع الإسكان الدور الذي يسهل ويحفز ويدعم أنشطة القطاع الخاص في مجال الاستثمار في الاسكان. وفي أثناء مرحلة إعداد الإستراتيجية العالمية للمأوى ثم تطوير مجموعة من المؤشرات الإسكانية بجهد مشترك من البنك الدولي ومركز

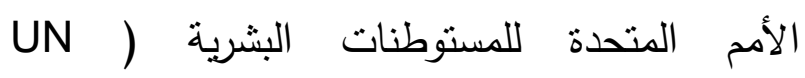
(HABITAT وذللك في عام •99 ام حيث تضمن هذا البرنامج مقارنة مفصلة لواقع الإسكان في ثناث وخمسين مدينة رئيسية موزعة في اثتتين وخمسين

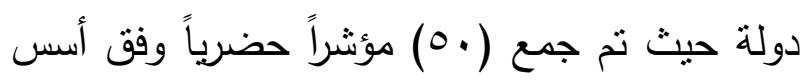
علمية وقابلة للمقارنة فيما بينها. 
الكوادر والتدريب والتعليم ... إلخ لتوفير الحاجات الأساسية للإنسان [^]']

r-1 أغراض المؤشر الحضري

تحقق المؤشرات الحضرية العديد من

الأغراض، فهي تقبس وتتابع معدل الإنجاز في تتفيذ إستراتيجيات وسياسات وبرامج التتمية بمدينة أو إقليم ما، كما أنها تمد متخذ القرار بالمعلومات الثاملة والمتكاملة عن حقيقة الوضع الراهن في المدينة أو لو الإقليم، فهي تعمل بمثابة المرشد له في تحديد الأهداف والأولويات لخطط التنمية، كما أنها ترفع علامات التحذير في وقت مبكر من تطبيق أي خطة

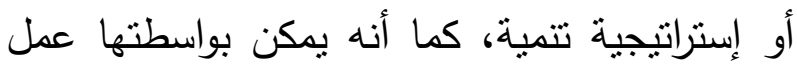
مقارنة بين التجمعات العمرانية عرضياً (عبر أماكن مختلفة) أو طولياً (عبر فنرات زمنية مختلفة)، وهي أيضاً ترفع مستوى إدراك المواطن بحقيقة التتمية المستدامة في المدينة أو الإقليم، وتمثل المؤشرات الحضرية الجانب التحليلي في التخطيط ولذلك فإن مصداقيتها وثباتها بمثلان أمراً حيوياً عند اختيارها كأدوات تخطيطية[‘'] ولكي تكون المؤشرات ناجحة في مهنها يجب أن تكون مرشداً فعالاً في عملية التغيير (change) في أولويات المجتمع، والتغيير في عملية اتخاذ القرار ورسم السياسات، والتغيير في سلوك الأفراد و والمؤسسات، وبوجه عام بركن للمؤشرات الحضرية أن تشاعد في المجالات النالية:
بممارسة الشراكة وتنبي طرق للتمكين وتطبيق وسائل المشاركة الفاعلة في عمليات التخطيط والإدارة وبناء القدرات لجميع الثركاء ومتابعة تقدم الإنجاز نحو الوصول للأهداف المعلنة للموئل عن طريق بناء شبكة اتصالات وتطبيق أحدث الثقنيات المتاحة. ع- برنامج المؤشرات الحضرية الثالث: ويبدأ بمرحلة ما بعد مؤتمر مدينة إسطنبول في عام 1997 ام ويطلق عليه اسم (مؤشرات إسطنبول +

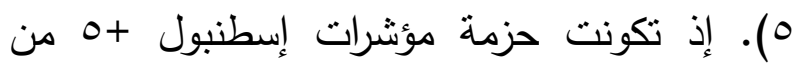

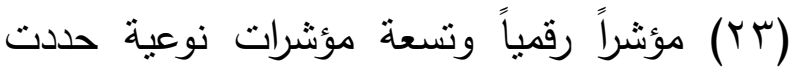
لتوافق البنود العشرين الأساسية لجدول الموئل الثاني ولتقييس الثقدم في الأداء في تطبيق جدول أعمال الموئل، كما أنها توفر للمدن حزمة مؤشرات يتيح استعمالها إعطاء صورة شاملة عن الوضع الحضري لهري في المدينة، ويمكن قياس الاداء والمقارنة بين هذه إعهاء

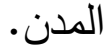

0- تطوير دليل التتمية البشرية بالتعاون مع

الثركاء في التتمية البشرية وهم ثلاثة مجموعات: المجموعة الأولى: المسئولون الرسميون للحكومة سواء المركزية أو المحلية، المجموعة الثانية: القطاع الخاص والمؤسسات التمويلية ورجال الاعمال والمسئولين في الغرف التجارية الصناعية، المجموعة الثالثة: مؤسسات المجتمع المدني المختلفة لتحقيق أهداف التتمية التي تركز على العنصر البشري باعتباره غاية التتمية من خلال التركيز على تأهيل 
المرصد الحضري العالمي التابع لبرنامج الأمم المتحدة للمستوطنات البشرية (UN HATAT)، وكذللك الاعتماد على البنك الدولي في تصميم وإعداد قاعدة البيانات اللازمة لإنتاج مجموعة من المؤشرات

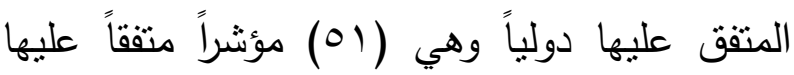
دولياً. كما تتتج أغلب الددن والأقاليم مؤشرات خاصة بها تعكس خصوصية هذه المدينة أو هذه المنطقة. وتختلف عدد المؤشرات التي تتنجها كل مدينة عن الأخرى حسب خصوصية كل مدينة ومدى توافرها في تلاك المدينة[·" مدينة

ويمكن تصنيف المؤشرات الحضرية إلى

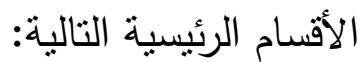

1- مؤشرات مناحة (مباشرة) وهي تلك المؤشرات المتوفرة من مصادرها أو التي يمكن إنتاجها بجه محدد من خلال البيانات الإحصائية المتاحة من مصادرها الثانوية المحدثة.

r- المؤشرات التي تحتاج إلى معالجة وإعادة إنتاج عبر التواصل مع الجهات المختلفة (مصادر

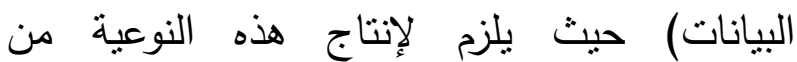
المؤشرات تتسيق مع مصادر البيانات ومعالجتها

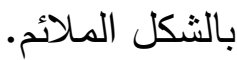

r- مؤشرات المسح الميداني وهي تلك المؤشرات التي لا تتوافر بياناتها من أي جهة
1- تغذية الإعلام المحلي: فيمكن أن تمد المواطن العادي والمتخصص بمعلومات دقيقة عن التتمية في المدينة أو الإقليم والآثار المتوقعة في المدى البعيد والخطوات التي يمكن اتخاذها حيال ذلك.

r- رسم سياسات وإستراتيجيات التتمية: فهي تمد متخذ القرار بصورة شاملة ومتكاملة عن حقيقة الوضع الراهن بالمدينة أو الإقليم مما يمكنه من

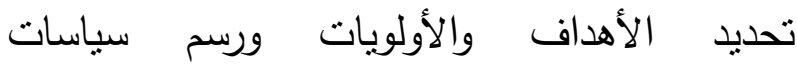
واستراتيجيات التتمية وتتفيذها ومتابعتها. ץ- تطوير أداء المجلس البلدي: فالمؤشرات تخدم متخذي القرار على كافة المستويات وتمكنهر من استخدامها كنقاط مرجعية لتقييم مدى النجاح في خطط التتمية ولتعديلها أو تغييرها بخطط بديلة إذا لزم الامر فئه وصولاً إلى مجتمعات أكثر رفاهية واستخامة. ع- تعليم النشء: يمكن أن تستخدم كأدوات لتعليم النشء عن التتمية المستدامة ترشدهم إلى الأدوار التي يمكن أن يقوموا بها في هذه المنظومة. 0- القضاء على مظاهر الانعزال القطاعي: حيث توجه قيم المؤشرات الحضرية المنتجة عدة قطاعات نحو العمل المشترك في ضوء وحدة

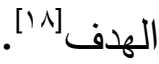
ب- - - تحلي وتصنيف المؤثرات الحضرية يتم تحديد المؤشرات الحضرية وفق مرجعية معينة وفي أغلب المدن يتم تحديدها وفق توصيات 
إعداد سياسة تتمية حضرية أكثز فعالية، ومساعدة المسئولين في فهم الاجتماعية والاقتصادية والعمرانية والسكانية والبيئية داخل المدن، واستخدام تلك المعرفة في إعداد خطط تتمية حضرية أكثر فعالية. وقد تجاوبت الكثير من الدول وعملت على إنثاء مراصد حضربة، بعضها على المستوى الوطني، والمسنوى الإقليمي، وبعضها على المستوى المحلي للمدن وخاصة المدن الكبرى، ولذا تعد التجارب العالمية في إنثاء المراصد الحضرية حديثة نسبياً [r]

وفي المملكة العربية السعودية عملت بعض أمانات المناطق منذ عام ب ...rم على إنشاء وتشغيل بعض المراصد الحضرية، ولقد كانت أمانة منطقة المدينة المنورة من أوائل الأمانات التي عملت على إنشاء وتشغيل المرصد الحضري لمدينة المدينة المنورة الذي أنتج (79) مؤشراً حضرياً تعكس واقع التتمية الحضرية في المدينة، تلا ذلك إنشاء مراصد حضرية محلية في بعض المحافظات التابعة لأمانة منطقة المدينة المنورة وهي ثمانية مراصد حضرية محلية أنتجت بعض المؤشرات الحضرية التي تعكس واقع التتمية في هذه المحافظات. كما عملت الهيئة العليا لتطوير مدينة الرياض على إنثاء المرصد الحضري لمدينة الرياض في عام 9 +. بام والذي أنتج (V^) مؤشراً حضرياً، وكذلك عملت أمانة
ويتطلب إنتاجها تتفيذ مسوح مبدانية للحصول على البيانات المطلوبة.

\section{ع - وصف وتحليل الوضع الراهن للمراصد الحضرية في المملكة العربية السعودية}

يتضمن هذا الجزء من البحث استعراضاً للوضع الراهن للمراصد الحضرية في المملكة العربية السعودية والتحديات التي تواجهها. ع- 1 المراصد الحضرية في المملكة العربية

\section{السعودية}

بعد أن اعتمدت الجمعية العامة للأمم المتحدة الوثيقة العالمية لأجندة الموئل الثاني، تم توجيه دعوة لجميع دول العالم للمشاركة في مؤتمر المؤئل الثاني الذي عقد في مدينة اسطنبول - بتركيا في عام 799 ام لإنشاء المراصد الحضرية الوطنية والمحلية، وتم توجيه الدعوة إلى جميع حكومات الدول بالعمل على متابعة تقدم أعمال إنتاج مؤشرات لقياس أداء التتمية الحضرية المستدامة للمدن.

وقد عمل المرصد الحضري العالمي بمركز الأمم المتحدة للمستوطنات البشرية UN (HABITAT الحكومات والسلطات المحلية والمجتمعات المدنية في مجالات جمع وتحليل وإدارة البيانات والمعلومات وإنتاج المؤشرات الحضرية، وذللك بإنشاء مراصد حضرية وطنية وإقليمية ومحلية يمكنها المساهمة في 
البيانات والمعلومات الرئيسية المطلوبة، وتوفير المنهجيات المتبعة عالمياً في تحليل البيانات للخروج بالمؤشرات الحضرية التي تعكس واقع التتمية في هذه المدن. أما المراصد الحضرية الأخرى في لعنديه المملكة فوضعها الراهن إما أنها في مرحلة إنهاء الهمراه الهريه إجراءات التعاقد في بعض منها مثل المرصد الحضري لمحافظة القطيف والمرصد الحضري لهفي لمحافظة عرعر ومحافظة عنيزة وإما جاري العمل على إنشائها وتتشغيلها مثال على ذلك المراصد الحضرية في مدينة أبها والباحة، والبعض الآخر منها أنهي أو في مراحله النهائية من إنهاء المرحلة

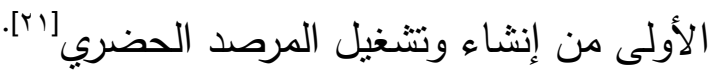
ويوضح الجدول رقم (1) في الملحق رقم (1) الوضع الراهن لإنشاء وتتغيل وإدارة المراصد الحضرية في المملكة العربية السعودية من خلاه (تحديد الجهة المسئولة عن تشغيل وإدارة المرصد الحضري، وحالة المرصد الحضري الحالية، ونوع

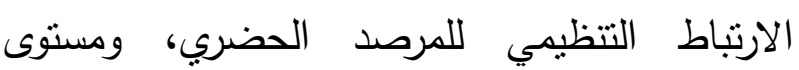
التشغيل، وعدد المؤشرات الحضرية، وآلية جمع ولاتط البيانات والمعلومات، و وآلية تحليل البيانات والمعلومات، وكذلك آلية تبادل المعلومات ومقارنة المؤشرات الحضرية) على النحو التالي: أولاً: الجهات المسئولة عن إنثاء وتتشغيل المراصد الحضرية في

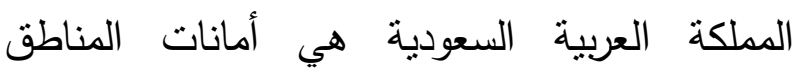
والبلديات من خلا التعاقد مع مكاتب استشارية
منطقة مكة المكرمة على إنشاء وتتغيل المرصد الحضري لمدينة مكة المكرمة في عام ^ .. بام وأنتج

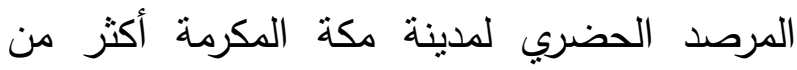

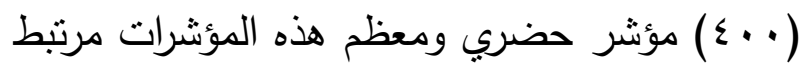
بطبيعة مدينة مكة المكرمة وقضايا الحج والعمرة المتعلقة بالمدينة، كما عملت أمانة محافظة جدة في تلك الفترة على إنثاء وتتشيل المرصد الحضري لمحافظة جدة والذي أنتج (•^) مؤشراً حضرياً، وعملت أمانة منطقة القصبم على إنشاء المرصد

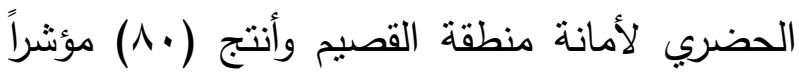
حضرياً، والمرصد الحضري في أمانة منطقة عسير

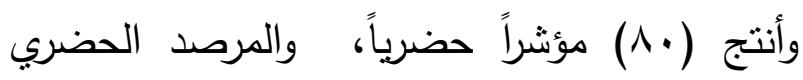

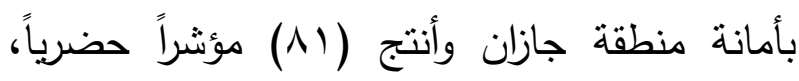
وتعد هذه المراصد الحضرية في مرحلة منقدمة عملية الرصد وإنتاج المؤشرات الحضرية والتقارير الدورية. ولقد عملت أمانات المناطق في هذه المدن على التعاقد مع بعض المكاتب الاستتارية

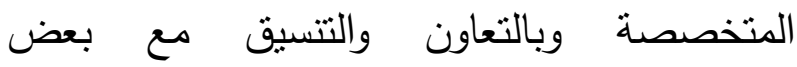
المؤسسات الدولية منل برنامج الأمم المتحدة ولئك للمستوطنات البشرية (UN HABITAT)، والمرصد الحضري العالمي - بمدينة نيروبي بكينيا، وبعض المؤسسات الإقليمية مثل المعهد العربي لإنماء المدن لئن الذين قدموا الدعم والمساندة لهذه المكاتب في تحديد القضايا الرئيسية للنتمية في هذه المدن ، وكذللك تقديم الدعم والمساعدة في عملية جمع وتحليل 
(0) مؤشراً حضرياً، تغطي عدداً من المحاور الرئيسية المتعلقة بالتتمية الحضرية وهي نتشمل على لنى سبيل المثال وليس الحصر الخفية العامة للبيئة الحضرية، والبنية التحتية، والإسكان، والإدارة المحلية، وتوطين الوظائف.....إخخ وعدد من المؤشرات الخاصة بكل مدينة أو منطقة منل محور الحج

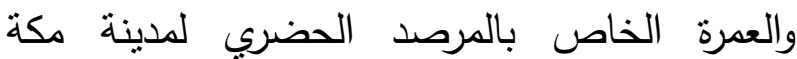
المكرمة والمرصد الحضري لمنطقة المدينة المنورة،

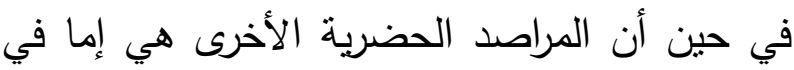
مرحلة التعاقد أو المراحل الأولية للإنثاء والتشغيل للمرصد الحضري. ولقد عملت بعض الأمانات والبلديات إلى تحويل إدارة المعلومات الحضرية إلى إدارة متخصصة تعنى بمتابعة سير عمل المرصد الحضري كمثال على ذلك أمانة منطقة حائل، وأمانة محافظة الأحساء، وبلدية حفر الباطن، سادساً: آلية جمع البيانات تتم في معظمها من خلال الوسائل والطرق التقليدية أما من خلال ضوابط الاتصال في الجهات المعنية الحكومية أو الخاصة المعنية بنوفير المعلومات، أو التقارير الدورية التي تتشرها بعض هذه الجهات، وإما الييانات التي لا يمكن الحصول عليها مباشرة من الجهات المعنية يتم جمعها من خلال المسح الميداني، سابعاً: آلية التحليل للبيانات والمعلومات للمراصد الحضرية الكبرى في المملكة مثال على ذلك المرصد الحضري لأمانة منطقة المدينة المنورة، والمرصد الحضري لمدينة مكة
متخصصة وبالتعاون مع بعض الجهات الدولية والإقليمية ذات العلاقة في عملية الرصد وتحديد القضايا الرئيسية للتتمية وطرق وأساليب جمع البيانات والمعلومات وتحليليها وفق منهجيات متبعة عالمياً، ثانياً: تجربة إنشاء وتثغيل المراصد الحضرية هي وني تجربة حديثة في بعض المراصد الحضرية، والبعض الآخر تعتبر التجربة متقدمة نوعاً ما ولديها تجربة أكثر من ^ سنوات في عملية الرصد، وعملية جمع البيانات والمعلومات، وإنتاج المؤشرات الحضرية وتظويرها وفق تحديد دقيق للقضايا المهمة وإصدار

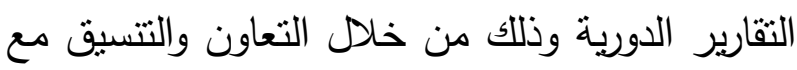
بعض الجهات الدولية مثل برنامج الأمم المتحدة للمستوطنات البشرية (UN HABITAT)، وبعض المؤسسات الإقليمية ذات العلاقة منل المعهد العربي لإنماء الددن. ثالثاً: معظم المراصد الحضرية في الحئ المملكة هي مراصد حضرية محلية على مستوى المدن والحواضر وليس لها أي ارتباطات تتظيمية مع هريه مراصد حضرية أخرى داخلياً وخارجياً، رابعاً: مستوى لياطي التتغيل لمعظم المراصد الحضرية في المملكة هو محلي من خلال مكاتب استتارية متخصصة بعقود مدتها سنة ونصف أو سنتان تتجدد تلقائياً منتى توفرت منات الميزانيات والاعتمادات المالية اللازمة لها، خامساً: معظم المراصد الحضرية وبالأخص المراصد الحضرية في الددن الكبرى لديها مجموعة من

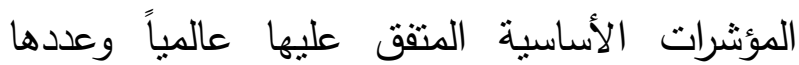


المراصد الحضرية منها على سبيل المثال لا الحصر

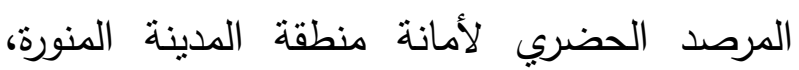
والمرصد الحضري لمدينة مكة المكرمة، والمرصد الحضري لمدينة الرياض، والمرصد الحضري لأمانة محافظة جدة والتي حصلت على بعض الجوائز العالمية. كما توضح الدراسات التحليلية للبيانات المتاحة عن تجارب بعض المراصد الحضرية في المملكة إلى أن تلك التجربة تواجه العديد من بهن التحديات والمعوقات وعدم شموليتها واستمراريتها بشكل عام نظراً لقلة الدعم المالي والميزانيات المرصودة لها، وكذلك ضعف الموارد البشرية المتخصصة والمؤهلة التأهيل المناسب وبالأخص الموارد البشرية الوطنية، إذ إن غالبية العاملين مع الاستشاريين الذي يشغلون هذه المراصد الحضرية

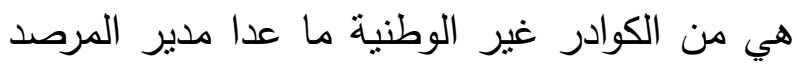
الحضري وبعض المساعدين الإداريين. هذا فضلاً عن ضعف اهتمام وإدراك بعض المسئولين في بعض أمانات المناطق والهحافظات بأهمية المراصد الحضرية لعملية التتمية الحضرية المستدامة وتوجيه السياسات والخطط والبرامج التنموية في المدينة. كما أثنار بعض المسئولين في بعض الأمانات والبلديات

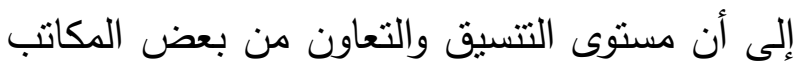
الاستتارية التي تعمل على إنشاء وتتغيل وإدارة بعض المراصد الحضرية في بعض المدن وبالأخص المدن الصغيرة والمتوسطة في المملكة مع بعض بهض
المكرمة، والمرصد الحضري لمدينة الرياض، والمرصد الحضري لأمانة محافظة جدة تتم وفق منهجية دقيقة تتوافق مع منهجيات الجهات الدولية والإقليمية التي أشرفت على إنشاء وتتشغيل هذه المراصد منل برنامج الأمم البشرية والمعهد العربي لإنماء المدن (UNHABITAT) وغيرها من المراكز الإقليمية والعالمية المعنية بالرصد الحضري...إلخ، أما المراصد الحضرية الأخرى في لهيه المدن الصغيرة والمتوسطة فمستوى التتسيق والتعاون فيها مع المؤسسات الدولية أو الإقليمية في عملية التحليل ضعيفين نوعاً ما، كما أن بعض البيانات التي لتهني يتم الحصول عليها من بعض الجهات المعنية تكون غير متوافقة مع متطلبات المرصد الحضري وفي بعض الأحيان تكون المعلومات غير محدثة ودقيقة مما يؤثر على دقة المؤشرات الحضرية التي يتم إنتاجها في هذه المراصد، ثامناً: آلية تبادل المعلومات والخبرات في معظم المراصد الحضرية المحلية تتم من خلا الوسائل التقليدية أي من خلا له المخاطبات الرسمية أو التقارير الدورية التي تتشرها بعض التصن المراصد الحضرية وهي غير مناحة إلكترونياً. وتتشير بعض اللقاءات مع بعض المسئولين في المراصد الحضرية والمعلومات المتوفرة عن تجربة بعض المدن في المملكة في عملية إنشاء وتشغيل وإدارة المراصد الحضرية واستتباط المؤشرات الحضرية إلى حداثة هذه التجربة باستثناء بعض ولن الترائ 
r- ترتبط المراصد الحضرية المحلية في أمانات المناطق والمحافظات فنياً بالمرصد الحضري الوطني.

r- تكون للمرصد الحضري الوطني عدد من المهام منها: إجراء الدراسات المقارنة للمؤشرات الحضرية بين المناطق والمحافظات، والعمل على جمع البيانات والمعلومات المتعلقة بالمؤشرات الحضرية وتحليلها، وتطوير نظام تقفي لتدفق البيانات والمعلومات إلكترونياً بما بسهل للجهات الحكومية عملية الحصول عليها بيسر وبشكل دوري، وإعداد إطار المؤشرات الحضرية الوطنية بمشاركة المراصد الحضرية في المناطق والمحافظات والجهات الحكومية والقطاع الخاص ومؤسسات المجتمع المدني [rr]

\section{ع - تجارب لبعض المراصد الحضريةة المحلية في المعلكة العربية السعودية}

نشأت فكرة المراصد الحضرية في المملكة العربية السعودية في الأساس من خلال مركز الأمم المتحدة للمستوطنات البشرية (الموئل) لتقييم الأوضاع واتجاهات التحضر العالمي. وتعد المملكة العربية السعودية من أوائل الدول في العالم العربي التي بدأت في إنشاء المراصد الحضرية المحلية منذ

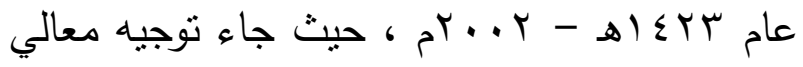
وزير الثئون البلدية والقروية (السابق) بإنشاء مراصد حضرية في كل مناطق المملكة ومدنها الرئيسية ، ثم
الجهات الدولية والإقليمية المعنية بتوفير الدعم والمساندة لهذه المراصد الحضرية ضعيفة نوعاً ما. ويجدر الإثارة إلى أن معظم المراصد الحضربة في المملكة تعاني من ضعف التتسيق وتعاون بعض الجهات الحكومية والخاصة المعنية بتوفير البيانات والمعلومات المطلوبة منها وبشكل دوري وفي الوقت المطلوب لها، كما أن عملية المسح الميداني للحصول على بعض البيانات غير المتاحة نتطلب وقتاً وطويلاً وتكلفة عالية مما يؤثز بشكل كبير في عملية إنتاج المؤشرات الحضرية في الوقت المحدد ل ل الها وبالدقة المطلوبة. وعلى الرغم من صدور قرار مجلس الوزراء حديثاً بإنشاء المرصد الحضري الوطني بقرار من

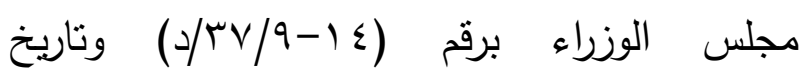

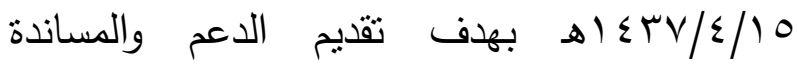
للمراصد الحضرية المحلية والتسيق فيما بينها وبينها وبين المرصد الحضري الوطني والمراصد الحضرية الإقليمية والعالمية إلا أنه حتى نهاية عام VT؟ اهـ لم يتم تشغيل وتفعيل هذا المرصد والذي ينص قرار إنشائه إلى ما يلي:

1- تتشأ وحدة تتظيمية بوزارة الثؤون البلدية والقروية بمستوى إدارة عامة ترتبط بوكالة الوزارة لتخطيط المدن، باسم "المرصد الحضري الوطني" يكون هو المرجع الرئيس لكل ما يتعلق بعملية الرصد الحضري في المملكة. 
العلاقة من القطاعين العام والخاص لتحديد أهم القضايا التي تواجه التتمية الحضرية في المنطقة

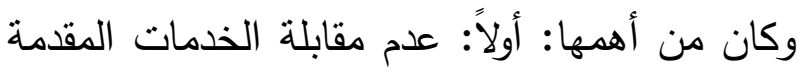

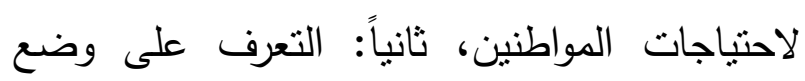
الخدمات الحالية ومدى توفرها وكفاءتها وسهولة لاهنية

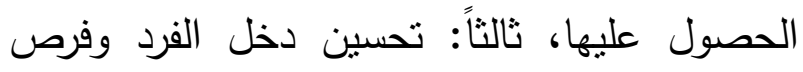

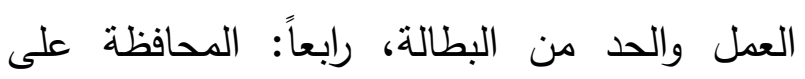

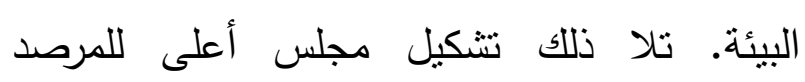
الحضري برئاسة أمير المنطقة وعضوية الجهات الحكومية والخاصة المعنية بالتتمية في المدينة، ويتبع المرصد الحضري ثمانية مراصد حضرية بله محلية على مستوى المحافظات يرأسها المحافظ. ويهدف هذا المجلس إلى إعداد السياسات والإستراتيجيات المستقبلية لتطوير أعمال المرصد إعداد الحضري بالمنطقة، وتحديد القضايا والموضوعات ذات الأهمية التي يتبناها المرصد الحضري، وندي، واعتماد

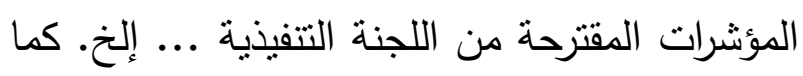
تم نشكيل اللجنة التتفيذية للمرصد الحضري لمناقثنة

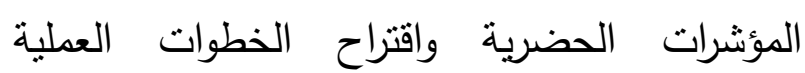
لمعالجة المشكلات التي ثبرز ، ومتابعة بناء القدرات

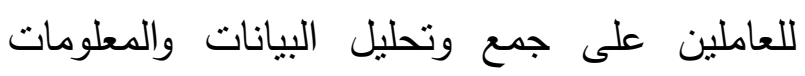

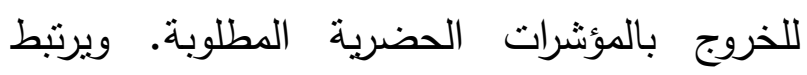
باللجنة التتفيذية مركز المرصد الحضري برئاسة أمين عام المرصد الحضري ويرتبط به المراصد

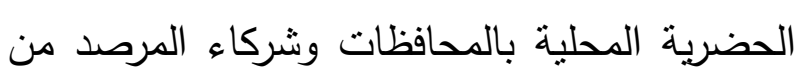

جاء تعميم صاحب السمو الملكي النائب الثاني وزير الاخلية الأمير/ نايف بن عبد العزيز (رحمه الله)

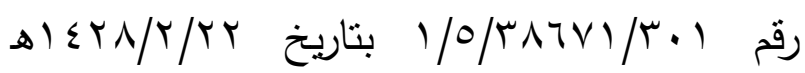
الموجه لأمراء المناطق بأن وزارة الثئون البلدية

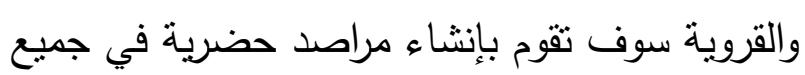

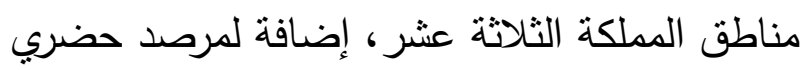
وطني مقره مدينة الرياض.

ويعتبر المرصد الحضري المحلي بمنطقة المدينة المنورة صاحب السبق في عملية إنثاء وتشغيل المراصد الحضرية بالمملكة، كونه أول مرصد تم إنثاؤه وتتغيله على مستوى المملكة العربية السعودية وتم ذللك بدعم ومساندة من برنامج

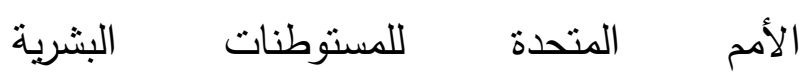
والمعهد العربي لإنماء المدن تلا لأل ذلك إنشاء وتتغيل المرصد الحضري لمدينة مكة

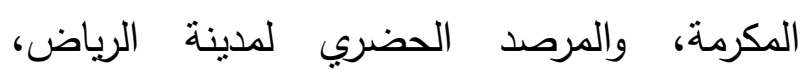

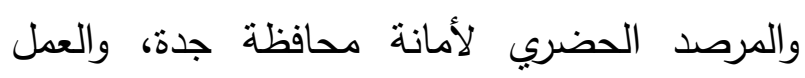
جاري على إنشاء وتشغيل المراصد الحضرية في باقي مناطق ومدن المملكة. ع-r-1 المرصد الحضري لأمانة منطقة الددينة الدنورة

بدأ العمل في المرصد الحضري لأمانة منطقة المدينة المنورة بداية قوية بدعم وتوجيه من أمير المنطقة وأمين منطقة المدينة المنورة، ولقد تم عقد عدد من اللقاءات وورش العمل مع المعنيين وذوي منيه 


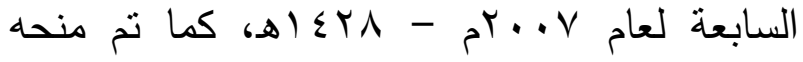
جائزة الثرف للإنجاز المتميز والتي يمنحها برنامج الأمم المتحدة للمستوطنات البشرية (الموئل) وذللك تقديراً للريادة التي أثنتها ولتميزه في مجال الرصد الحضري.

ولقد واجهت تجربة المرصد الحضري لمنطقة

المدينة المنورة عدداً من التحديات التي تواجهها العديد من المراصد الحضرية في بداية مرحلة الإنشاء والتشغيل كما حددها مدير المرصد الحضري المهندس / محمد الفاروقي من عدم توفر بعض البيانات والمعلومات، وضعف التتسيق وتعاون بعض له الجهات الحكومية والخاصة في توفير المعلومة الدقيقة وفي الوقت المحدد لها، وضعف الموارد البشربة الوطنية المتخصصة والمدربة في على عمل المرصد الحضري، وضعف الميزانيات المرصودة وقلة الدعم المالي لمشروع المرصد الحضري، وضعف نطبيق وتوظيف التقنيات الحديثة في عملية تبادل المعلومات مع الجهات المعنية وذوي الثأن [إ..... S-r - المرصد الحضري لمدبنة مكة المكرمة كانت بداية فكرة المرصد الحضري لمدينة مكة المكرمة هي في عام ^ ... م ع عدما عقد برنامج

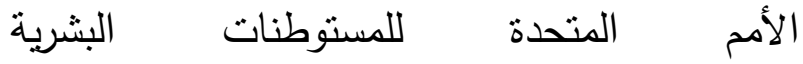
ورشة عمل بالتعاون مع بعض (UNHABITAT) الخبراء العالميين والمحلين لمناقثة فكرة إنشاء
الإدارات الحكومية والخاصة، ويرتبط به فرق العمل والوحدات الفنية للمرصد الحضري. ولقد عمل المرصد الحضري لمنطقة المدينة المنورة بالتسيق وتوصيات خبراء مكتب الأمم المتحدة الإنمائي والمعهد العربي لإنماء المدن على إنتاج (79) مؤشراً حضرياً تمت على ثلاثة مراحل: - المرحلة الأولى: مرحلة إنتاج المؤثرات المتاحة والتي تتوفر بيناتها مباشرة من مصادرها الأساسية.

- المرحلة الثانية: وهي مرحلة إنتاج مؤثرات الإدارات الحكومية والمجتمع المدني التي توفرت بياتها من مصادرها الأولية وبلغ عدد مؤشراتها (ع (ب) مؤشراً حضرياً. - المرحلة الثالثة: مرحلة إنتاج مؤشرات المسوح الميدانية والتي بلغ عددها (IV) مؤثراً حضرياً [rr] ولقد تم الانتهاء من ست دورات للمرصد الحضري لمنطقة المدينة المنورة بواقع سنتين لكل دورة تم خلالها إنشاء قاعدة بيانات للمرصد الحضري، وإصدار مجموعة من التقارير السنوية، وتدريب عدد من الكوادر البشرية الوطنية على عملية جمع وتحليل البيانات والمعلومات وإنتاج المؤشرات الحضرية. وقد حاز المرصد الحضري على الجائزة الأولى لمنظمة العواصم والمدن الإسلامية في دورتها 
المرصد الحضري في أداء مهامه. ويتبع للمجلس الأعلى مجلس تتفيذي بتولى منابعة عملية جمع البيانات وتحديد أساليب تصنيفها وتحليلها، وتحديد نطاق توزيعها. كما يتبع المجلس التنفيذي جهاز فني يتكون من متخصصين في الدراسات العمرانية، والدراسات السكانية والاجتماعية، والتحليل الإحصائي، ونظم المعلومات الحضرية، ويتولى ولى وضع معايير وأساليب جمع ومعالجة البيانات

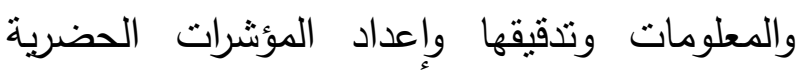
وربطها تقنياً بنظم المعلومات الحضرية.

ولقد عمل المرصد الحضري لمدينة مكة المكرمة وبالتتسيق مع برنامج الأمم المتحدة الإنمائي على إنتاج (10) مؤشراً حضرياً متفق عليها عالمياً، وهي الحد الأدنى لنتخيص الوضع الحضري لأنتراي

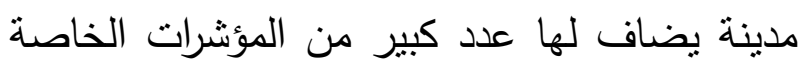
بمدينة مكة المكرمة، وهي مؤشرات متعلقة بالحج، ومؤشرات متعلقة بالعمرة، ومؤشرات متعلقة بالعشوائيات، ومؤشرات متعلقة بالأحياء السكنبة، وقد بلغ عدد المؤشرات الحضرية للمرصد الحضري الرئيسي لمدينة مكة المكرمة والمراصد التابعة له له

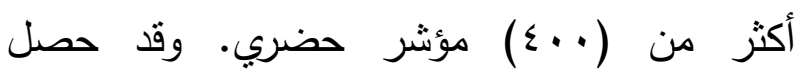
المرصد الحضري لمدينة مكة المكرمة على جائزة الأيزو من ضمن أفضل عشرة مراصد حضرية حول لمرله العالم حسبت مؤشراتها الحضرية وفق معايير الأيزو

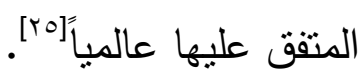

المرصد الحضري لمدينة مكة المكرمة بهدف رصد

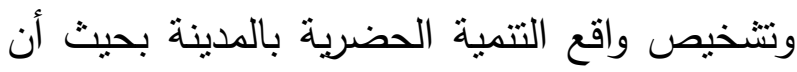
يتولى المرصد الحضري عملية جمع البيانات عن الحالة الحضرية في المدينة والانشطة السكانية والاقتصادية والاجتماعية المختلفة، والخروج منها بمؤشرات تعكس واقع التتمية الحضرية في المدينة، وتكون عبارة عن جهاز استشاري وداعم للقرار المحلي لمعدي الخطط والسياسات التتموية في المدينة. ويتكون المرصد الحضري لمدينة مكة

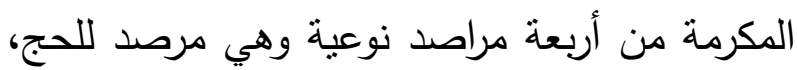

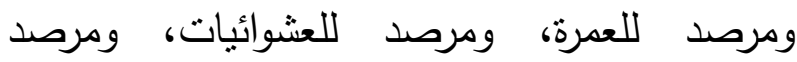
للأحياء لمدينة مكة المكرمة. ويهدف المرصد الحضري لمدينة مكة المكرمة إلى توفير مجموعة من مؤشرات كمية ونوعية تقدم

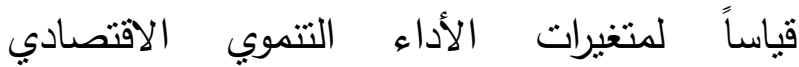
والاجتماعي في المدينة بما يساهم في تحقيق التتمية الحضرية المستدامة، ومتابعة تحليل المؤشرات الحضرية وتحديثها بما يلائم خصوصية المجتمع

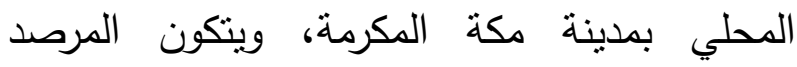
الحضري من مجلس أعلى يرأسه أمير المنطقة، ويمثل فيه جميع رؤساء الإدارات الحكومية والجهات الخاصة ومؤسسات المجتمع المدني الفاعلة في روني المدينة، ويتولى هذا المجلس تحديد القضايا ذات الأولوية للتتمية، واتخاذ القرارات بشأن اتجاهات عمل هلئل المرصد الحضري، واعتماد حزم المؤشرات، ومساندة 
لتحديد متطلبات وآليات إنشاء ونتشغيل المرصد الحضري، وتحديد البرنامج الزمني والخطوات المستقبلية لتتغيل المرصد الحضري. وفي عام ع إ اهـ تم إقرار الهيكل التنظيمي للمرصد الحضري لمدينة الرياض الذي يتكون من مجلس ولجنة تتفيذية ومركز للمرصد الحضري. ويترأس مجلس المرصد الحضري أمير المنطقة وعضوية أربعة عشر عضواً ويتولى مجلس المرصد الحضري التالي: أولاً: إقرار القضايا ذات الأولوية في التنمية الحضرية، ثانياً: اتخاذ القرارات بشأن اتجاهات العمل في المرصد الحضري، ثالثاً: إقرار آليات تطوير الإستراتيجيات والسياسات والثقييم والمتابعة للمرصد الحضري، رابعاً: اعتماد التقارير الدورية للمراصد الحضرية والمؤشرات الحضرية. ويرتبط بمجلس المرصد الحضري اللجنة التتفيذية التي تتولى عملية إعداد مناهج وبرامج عمل المرصد الحضري، وتوفير البيانات والمعلومات للمرصد الحضري واعتماد صحة ودقة البيانات المقدمة من الجهات، وتحديد حزم المؤشرات الحضرية، وحضور ورش العمل والاجتماعات الدورية للمرصد الحضري. وتتبع اللجنة التنفيذية للمرصد الحضري مركز المرصد الحضري ويتكون من فرق العمل التي تقوم بمراجعة وتجميع البيانات، والإعداد لجدول أعمال اللجنة التتفيذية، والوحدات الفنية بالمرصد الحضري التي ينم من خلالها وضع منهجية اختيار مؤشرات الرصد
ولقد واجهت تجربة المرصد الحضري لمدينة مكة المكرمة عدد من التحديات التي تواجهها العديد من المراصد الحضرية في بداية مرحلة الإنشاء والتتغيل ومن أهمها كما حددها مدير المرصد الحضري المهند / أحمد الخلاقي ضعف التعاون والتتسيق مع بعض الجهات الحكومية والخاصة في توفير البيانات والمعلومات المطلوبة والدقيقة وفي لي الوقت المحدد لها، وضعف الموارد البشرية الوطنية المتخصصة والمدربة في على عمل المرصد الحضري، وخصوصاً المتخصصين في المجال الفني لعمل المرصد الحضري من إحصائيين ومتخصصي تقنية معلومات، وتدني الدعم المالي لمشروع المرصد الحضري، وضعف اهتمام بعض المسؤولين في الأمانات بالمرصد الحضري وأهمية المؤشرات الحضرية لعملية دعم القرار وتوجيه السياسات والخطط والبرامج التتموية، وضعف تطبيق وتوظيف التقنيات الحديثة في عملية تبادل المعلومات والخبرات مع الجهات المعنية وذوي الثنأن . ع-r-r الهرصد الحضري لعدينة الرياض بدأت الهيئة العليا لتطوير مدينة الرياض أول خطواتها لإنثاء وتتشيل المرصد الحضري لكدينة

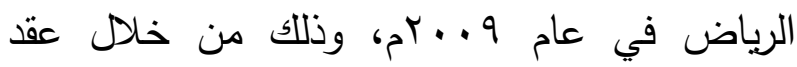
ورشة عمل شارك فيها أكثر من خمسين من الجهات الحكومية والخاصة ومؤسسات المجتمع المدني 
لعدم إدرالك واهتمام بعض المسئولين والمعنيين بهذا الموضوع أهمية المرصد الحضري في عملية دعم القرار المحلي وتوجيه السياسات والخطط والبرامج التتموية في المدينة. كما عانى المرصد من صعوبة الحصول على بعض البيانات والمعلومات الدقيقة من بعض الجهات الحكومية والخاصة وفي الوقت المحدد لها مما ينعكس سلباً على إنتاج المؤشرات الحضرية في الوقت المحدد لها وعلى دقة بعض لهض المؤشرات التي لا تتوفر لها المعلومات الدقيقة، وضعف في الموارد البشرية الوطنية المتخصصة لهصنا

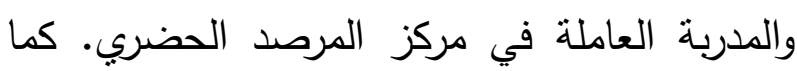

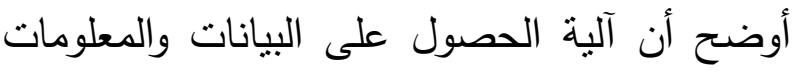
من الجهات تتم من خلال ضوابط الاتصال في تلك

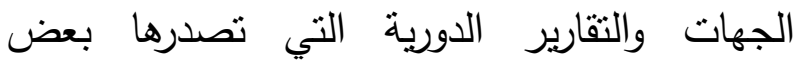

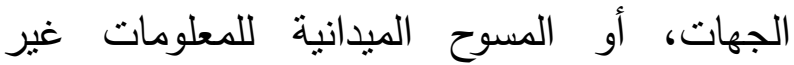
المتوفرة لدى الجهات المعنية، وأن عملية تبادل المعلومات والخبرات تتم من خلال الوسائل التقليدية من خلال المخاطبات والتقارير الدورية التي تتشرها

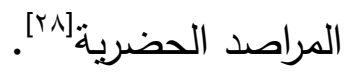

\section{ه- وصف وتحليل التجارب الدولية مقارنة بتجربة}

\section{المملكة العربية السعودية}

يتضمن هذا الجزء من البحث استعراضاً لتجارب بعض الدول العربية والعالمية في مجال إنشاء ونتشغيل وإدارة المراصد الحضرية والمؤشرات الحضرية وآلية جمع وتحليل البيانات والمعلومات
الحضري وآليات التحليل والمراجعة والتذقيق واختيار مجموعات المؤشرات و وإعداد التقارير والتتسيق

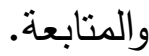

ولقد عمل المرصد الحضري لمدينة الرياض على إنتاج (V^) مؤشراً حضرياً، منها (10) مؤشراً

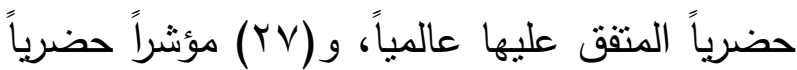
محلياً تعكس خصوصية مدينة الرياض نم اختبارها بناءً على صلتها المباشرة بسياسات المخطط الإستراتيجي الثامل لمدينة الرياض. ونت تقسيم المؤشرات الحضرية إلى المحاور التالية: أولاً: محور مؤشرات الخلفية العامة، ثانياً: محور مؤشرات التتمية الاجتماعية والاقتصادية، ثالثاً: محور مؤشرات البنية الأساسية، رابعاً: محور مؤشرات النقل، خامساً: محور مؤشرات المسكن الملائم، سادساً: محور مؤشرات إدارة البيئة، سابعاً: محور مؤشرات الإدارة

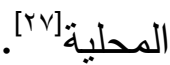

ولقد واجهت تجربة المرصد الحضري لمدينة الرياض الكثير من التحديات كما أوضحها المسئول عن المرصد الحضري المهندس / / عبدالرحمن السلطان من أهمها أن فكرة المرصد بدأت في عام

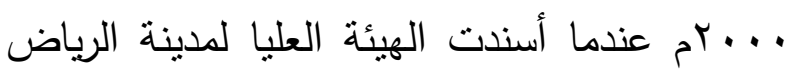
لخبراء المعهد العربي لإنماء المدن عمل دراسة لإنشاء وتتشغيل المرصد الحضري لمدينة الرياض، لكن لم ينم البدء في الخطوات العملية لإنشاء وتتغيل المرصد الحضري إلا في عام 9 . . rم نظراً 
المدن المشاركة بالعمل على إنشاء مراصد حضرية تقوم على رصد وتيرة التحضر في هذه الدول. إذ نم في البداية العمل على إنثاء المرصد الحضري الوطني بالهيئة العامة للتخطبط العمراني على شكل

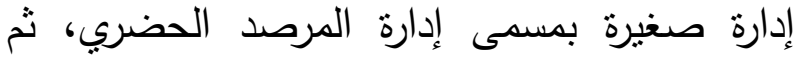

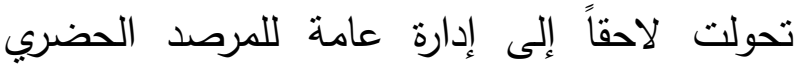
بالهيئة تشرف على جميع المراصد الحضرية بالأقاليم والمحافظات والمدن. في البداية نم العمل على إنشاء

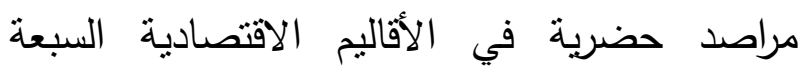
بمهورية مصر العربية، نلا ذلك إنشاء مراصد حضرية في بعض المحافظات السبعة والعشرين والمدن في جمهورية مصر العربية وعددها (اMM) مدينة.

وبرأس رئيس الهيئة العامة للتخطيط العمراني مجلس المرصد الحضري الوطني، ويرأس مديري

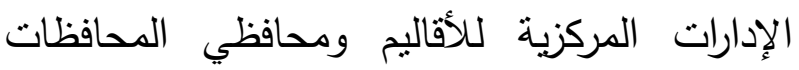
مجالس المراصد الحضرية على المستوى المحلي، ويشرفون على جميع الجهات الخدمية في الأقاليم والمحافظات [9 r]

وفي ضوء التوجهات العالمية وتوصيات الاجتماعات العربية والإقليمية والعالمية بأهمية إنشاء المراصد الحضرية على الصعيدين الوطني والمحلي، الصئل وكذلك أهمية إعداد المؤشرات الحضرية، فقد قامت الهيئة العامة للتخطيط العمراني بجمهورية مصر إعرات

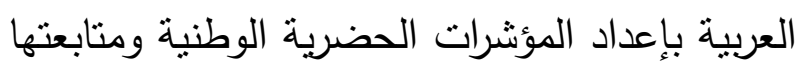

ومقارنتها بتجربة المملكة العربية السعودية، وفيما يلي عرض لبعض التجارب العربية والعالمية في مجال إنثاء وتتغيل وإدارة المراصد الحضرية التي لتئي عملت على إنشاء مراصد حضرية ولديها مؤشرات حضرية. وتختلف التجارب في نواحٍ كثيرة أهمها الاستمرارية، والقدرة على أداء المهمة الأساسية للمرصد الحضري في مساعدة المسؤولين وصناع القرار في مجال التتمية الحضرية، ومستوى المرصد الحضري، وارتباطه التنظيمي، والقضايا الرئيسية التي يركز عليها المرصد الحضري. ه- 1 التجارب العربية

يتتاول هذا الجزء استعراضاً لبعض التجارب العربية في مجال إنثاء وتتشغيل وإدارة المراصد الحضرية الوطنية والمحلية واسنتباط المؤشرات الحضرية وآلية جمع البيانات والمعلومات والتحديات ولهيه التي تواجهها ولقد تم اختيار الدول التي لها السبق والتميز في هذا المجال وكذللك الثبيه بتجربة المملكة مقارنة بباقي الدول العربية الأخرى التي لم تعمل بعد

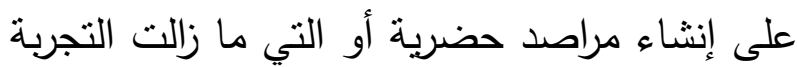
في بدايتها وفيما يلي عرض لبعض هذه التجارب: 0-1 - التجربة المصرية

بدأ العمل على إنشاء المرصد الحضري الوطني منذ مؤتمر إسطنبول - بتركيا في عام 1997 ام والتقرير الذي أوصى جميع الدول ومسئولي 
المؤشرات الحضرية وتبادل الخبرات عن طريق إعداد وتتظيم ورش عمل ودورات تدريبية بالتعاون مع المراصد الحضرية المحلية، وكذلك تبادل الخبرات الدولية على المستوى العربي والعالمي. ومن أبرز

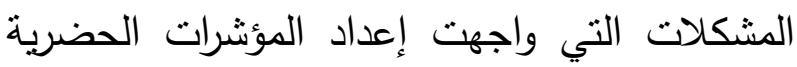
عدم توفر البيانات بصورة تفصيلية، وعدم وجود

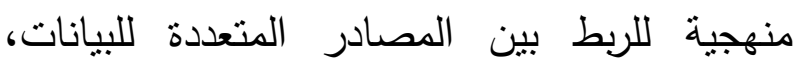
بالإضافة إلى عدم ملاعمة بعض المؤشرات العالمية للظروف الاجتماعية. ولقد أقيمت أول ندوة علمية حول المراصد الحضرية للدول العربية بجمهورية مصر العربية في مطلع عام 1991ام تحت رعاية الهيئة العامة للتخطيط العمراني. وفي عام 999 ام كلفّت الهيئة بإعداد المؤشرات الحضرية الوطنية لمصر ، وفي عام

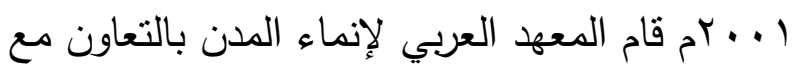
برنامج الأمم المتحدة للمستوطنات البشرية بدعم فني لمدينة طنطا لإنشاء مرصدها الحضري.

وفي عام ^ ^. rم ووفقاً لقانون البناء منحت الهيئة مسؤولية تطوير المؤشرات العمرانية وتحديثها بالتتسيق مع مراكز المعلومات على المستويات التخطيطية المختلفة. وفي عام 9. -. بم صدر قرار وزير الإسكان والمرافق والتتمية العمرانية بشأن تتظيم المراكز الإقليمية للتخطيط والتتمية العمرانية التابعة

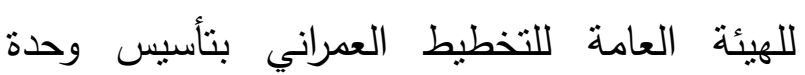
للمرصد الحضري بكل مركز إقليمي. وهكذا انتشرت
لتكون نواة لإنشاء المرصد الحضري الوطني. وقد عملت الهيئة العامة للتخطبط العمراني بدراسة منظومة المرصد الحضري الوطني المتفرع منه المراصد الإقليمية والمراصد المحلية، وتم تحديد المهام الأولية للمرصد الحضري الوطني فيما يلي: 1- وضع خطة عمل لإنشاء المراصد الحضرية والإقليمية والمحلية. r- تدريب الكوادر المحلية ورفع كفاءة

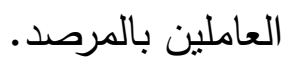

r- إعداد وتحليل المؤشرات الحضرية ومتابعتها وتطويرها بما يلائم خصوصية المجتمع

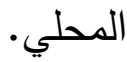
ع- رصد وقياس كفاءة السياسات التتموية الوطنية والمحلية من خلال المؤشرات الحضرية التي يتم تطويرها لتحقيق هذا الغرض. 0- تتظيم دورات ولقاءات تشاورية مع داءع الثركاء، وتتظيم لقاءات دورية (محلية وعربية). צ- ربط العمل بين المراصد المحلية مع كل من المراصد الإقليمية والمرصد الوطني، وكذلك ربط المرصد الحضري الوطني بالمرصد الحضري العالمي. V- إعداد الثقارير والنشرات الدورية[··] وقد قام المرصد الحضري الوطني بعقد مجموعة من الدورات التدريبية، وإعداد وتطوير ليطري 
لتغيير الظروف، وعدم الغموض، والاستقلالية). كما تم تحديد الفئات المستخدمة للمؤشرات من سكان المدن ومنتجي الخدمات والجهات المعنية بخدمات البنية التحتية والحكومات المحلية وادارات المدن والقطاع الخاص والمؤسسات التمويلية والمنظمات غير الحكومية[" آن

اعتمدت التجربة الأردنية على المشاورات والاجتماعات مع الخبراء في بناء المؤشرات حيث نم دمج نظام مؤشرات الإسكان بالمؤشرات الحضرية

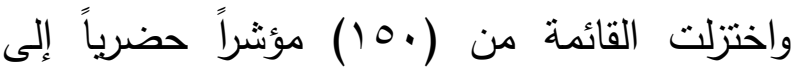
(7) مؤشراً حضرياً وقسمت المؤشرات إلى ثلاثة أقسام رئيسية، حيث تمثل مؤشرات البيانات الأساسية

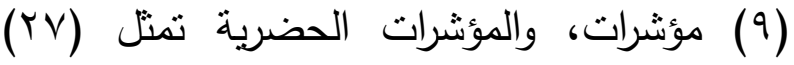

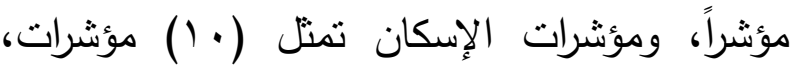
واعتبرت هذه المجموعة الأخيرة من المؤشرات مجموعة الحد الأدنى من المؤشرات للمقارنة بين المدن. وقد قام المرصد الحضري بوضع الهرم المعلوماتي الذي يبدأ بالبيانات في قاعدته وينتهي بالمعايير في قمته مروراً بالإحصاءات والمؤشرات. وقام بتقسيم المؤشرات إلى جزأين، يتضمن الجزء الأول برنامج المؤشرات الإسكانية والجزء الثناني يتضمن برنامج المؤشرات الحضرية، وقد استهدف برنامج مؤشرات الإسكان رصد ومراقبة قطاع الإسكان، وحددت مصادر معلومات تلأك المؤشرات
المراصد الحضرية بالمدن المصرية تحت رعاية الهيئة العامة للتخطيط العمراني [9"]

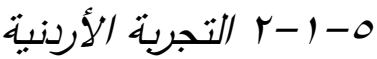

بدأت التجربة من خلال المؤسسة العامة للإسكان والتطوير الحضري بتطبيق برنامج المؤشرات الإسكانية لاستعماله في مراقبة ورصد قطاع الإسكان في المملكة، ولتنفيذ توصيات الإستراتيجية الوطنية للإسكان. وقد أنتجت المؤسسة العامة للإسكان والنظوير الحضري تلك المؤشرات منذ عام بو9 ام لمدينة عمان الكبرى وذللك بالتعاون مع البرنامج الإنمائي للأمم المتحدة، وركزت الماته المؤسسة على · ا مؤشرات إسكانية رئيسية تقييس التغيرات الأساسية في مجال العرض والطلب والتمويل للمساكن. وتسعى المؤسسة العامة للإسكان والتطوير الحضري لتعميم برنامج المؤشرات

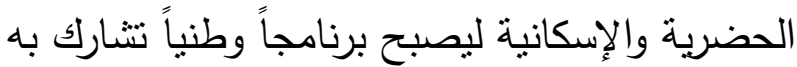
كافة الجهات واستخدامه أداة لبناء قاعدة معلومات الددن ولتقييم أداء قطاعات التتمية المختلفة بها، ومن أهم أهداف المرصد الحضري تحديد وجمع المؤشرات، وتطوير قاعدة بيانات تسمح بالتحليل، ومساعدة الدول الأخرى في استخدام وتطوير برنامج المؤشرات الحضرية. كما تم وضع المعايير التي تم اختيار وتحديد المؤشرات الحضرية بناءً عليها وهي لهمي

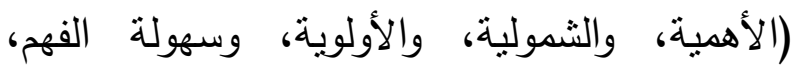
واقتصادية التكلفة، والقابلية لقياس، والحساسية 
r- عدم التحديث المستمر للبيانات مما

يصعب معه تحديث المؤشرات.

r- عدم توفر البيانات على مستوى المدن ومن ثم اللجوء إلى التقديرات الإحصائية.

؟- عدم توفر بعض المؤشرات المطلوبة

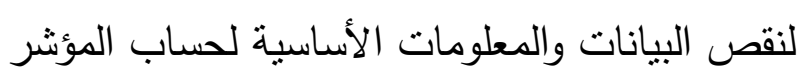

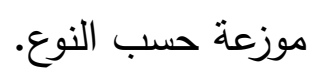
-1- - التجربة البحربنية

أقامت مملكة البحرين المرصد الحضري

الوطني عام • ب أهـ - 999 ام ، حيث نظمت وزارة

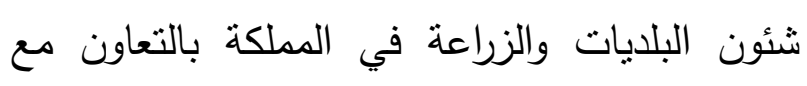

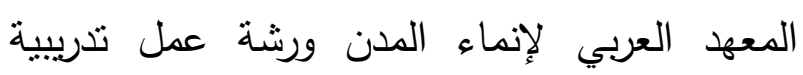

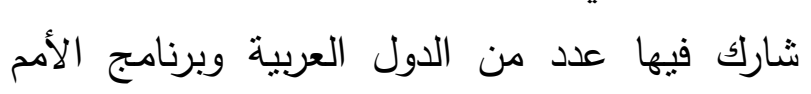
المتحدة للمستوطنات البشرية بعنوان إنثاء وتتشغيل

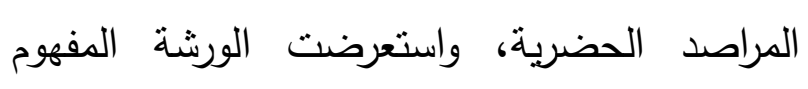
العلمي والمؤسسي للمراصد الحضرية والفرق بين الإحصاءات والمؤشرات، بالإضافة إلى شرح كيفية استخدام المؤشرات في عمليات الإدارة الحضرية

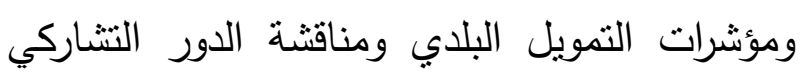

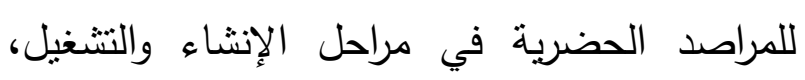

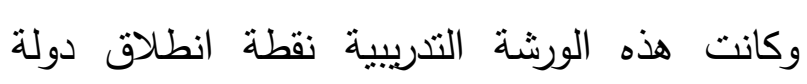
البحرين لإنشاء مرصدها الحضري. كان الهدف الرئيسي لبرنامج المؤشرات الحضرية

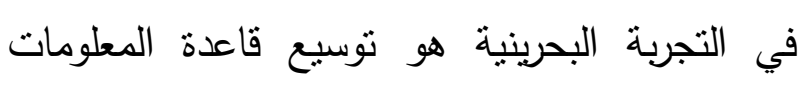

1- معلومات دورية سنوية.

r- معلومات تتغير بشكل تدريجي ولكن في

مدى زمني أطول، يكون مصدرها عادةً التعدادات أو لَّات المسوح الميدانية المتخصصة.

ومن أهم الصعوبات المتعلقة بالمؤشرات الإسكانية التي واجهات التجربة الأردنية جمع باله

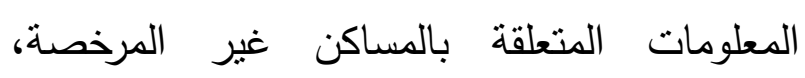
وصعوبة حساب المؤشرات المتعلقة بالتغير في قيمة

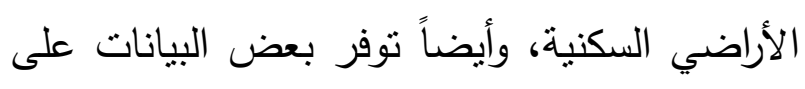

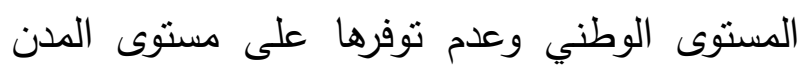

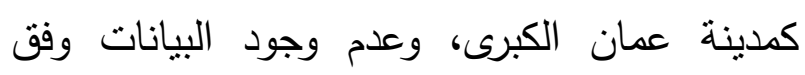
التعريف المحدد للمؤشرات المطلوبة. أما بالنسبة لبرنامج المؤشرات الحضرية الذي

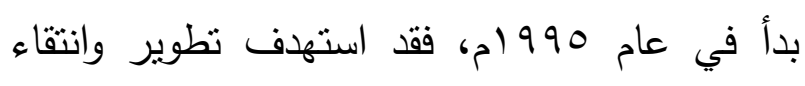
المؤشرات العالمية (10 مؤشراً) للمساهمة في إعداد السياسات العامة للتنمية الحضرية، كما تم تطوير مجموعة من المؤشرات الثاملة والتي تضم (Vo) مؤشراً كبدائل للمؤشرات الأساسية، ونتيجة للاراسات

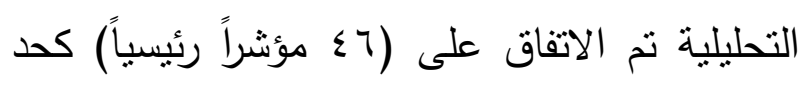

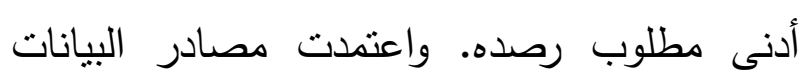
على التقارير والإحصاءات السنوية والأبحاث العلمية، ومن أبرز الصعوبات التي واجهت برنامج المؤشرات الحضرية بشكل عام ما يلي: اليرن 1- عدم توفر البيانات لحساب بعض المؤشرات. 
ولقد واجه المرصد الحضري في مملكة البحرين الكثير من التحديات تتلخص في عدم المقدرة على استدامة وصيانة استقلالية المرصد الحضري. ومن هنا ثأني أهمية استدامة مؤسسية

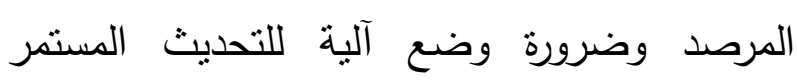
لتساعد صانعي القرار في روية الواقع ورسم سياسات المستقبل ومتابعة التتفيذ لها. 0-1 - تجربة إمارة دبي في دولة الإمارات العربية الدتحدة

تم إنشاء المرصد الحضري في إمارة دبي

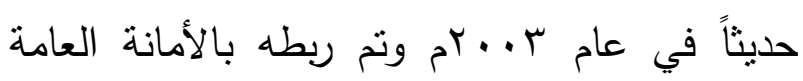
للمجلس التنفيذي التابع لحكومة إمارة دبي، وهو عبارة عن جهاز أساسي للاعم وتوجيه القرارات التتموية في الإمارة، ويرأس هذا المجلس سمو ولى لى لئ العهر وتثارك فيه جميع الجهات الحكومية التابعة لإمارة دبي، ويعتبر هذا الجهاز أعلى سلطة تتفيذية معنية بالتنمية الحضرية في الإمارة.

ويتولى المرصد الحضري بإمارة دبي جمع البيانات وتحليلها ومن ثم إنتاج المؤشرات التي يحددها المجلس التتفيذي كقضايا أساسية للتتمية الحضرية في الإمارة والمتعلقة بشكل أساسي بقياس الأداء في القطاعات التتموية المختلفة في الإمارة ومن ثم متابعتها

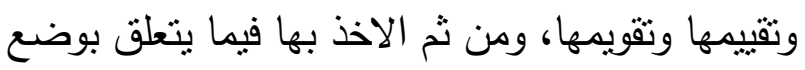
السياسات وخطط التتمية الحضرية في الإمارة. أما عدد المؤشرات التي يتم رصدها وإنتاجها ليس كبيراً إنما
لتطوير السياسات المساعدة في اتخاذ القرار من أجل تحسين أحوال المعيشة لسكان الحضر بالمملكة، بالإضافة إلى مجموعة الأهداف التالية:

1- تعريف واختيار المؤشرات الحضرية لقياس الأداء والتقام في القطاع الحضري. r- تطوير القدرات البشرية لأصحاب المصلحة الرئيسيين في البحرين. ץ- وضع إطار مؤسسي لبرنامج المؤشرات

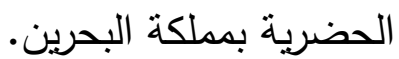

وتبلور دور برنامج الأمم المتحدة الإنمائي

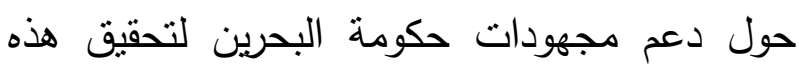

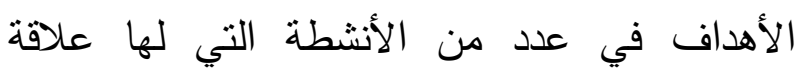
مباشرة أو غير مباشرة ببرنامج المؤشرات الحضرية وتلخصت أهم هذه الأنشطة فيما يلي: 1- دعم التخطيط الإقليمي. r- تطوير المستوطنات البشرية القائمة والحديثة. r- مساعدة وزارة الصحة. ع- المساعدة في إعداد خطة استعمالات الأراضي الوطنية البحرينية. 0- إنشاء قاعدة بيانات للنتمية البشرية المستدامة وتفعيلها. 7- دعم مشروعات المياه والبيئة بمملكة

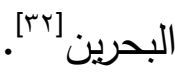


الحضرية في بداية إنثاء وعمل المراصد الحضرية.

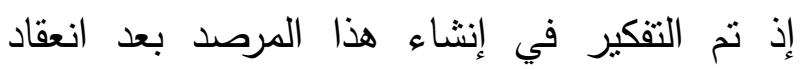
المؤتمر الذي تم تتظيمه من قبل البنك الدولي ومركز الأمم المتحدة للمستوطنات البشرية لتفعيل أجندة الموئل الأول الذي عقد بمدينة فانكوفر بمقاطعة لإنة

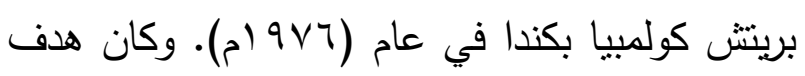
أجندة الموئل الأول هو تمكين المؤسسات الحكومية

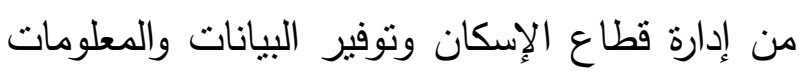

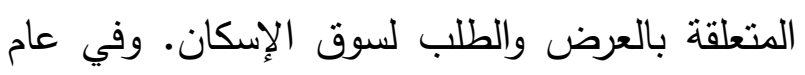
9 1919 أنثأ البنك الدولي ومركز الأمم المتحدة للمستوطنات البشرية برنامج مؤشرات قطاع المأوى.

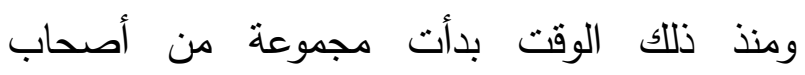
المصالح من مؤسسات المجتمع المدني والأكاديميين بالاجتماع لتحديد المؤشرات المطلوبة المتعلقة بتأمين المأوى المناسب لسكان المدينة والعمل على جمعها وتصنيفها وتحليلها واستتباط المؤنشرات الحضرية منها. كانت بداية عمل المرصد بداية بسيطة جداً من ولن خلا الجهود الذاتية لبعض المهتمين من الأكاديميين

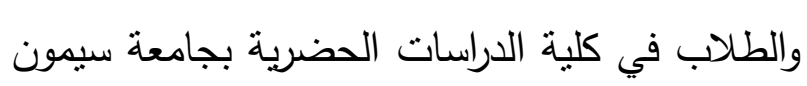
فريزر الخاصة بمدينة فانكوفر وبالتعاون مع مؤسسات

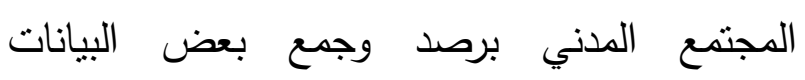

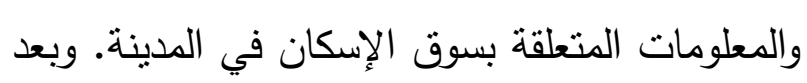
زيادة حجم العمل وزيادة عدد المؤشرات المطلوبة تم تتكيل إدارة بمسمى إدارة المرصد الحضري في كلية الدراسات الحضرية بالجامعة.
يركز بشكل أساسي على القطاعات التتموية التي ترى

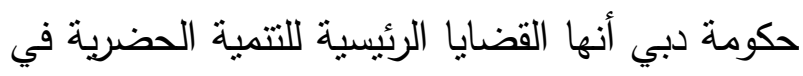

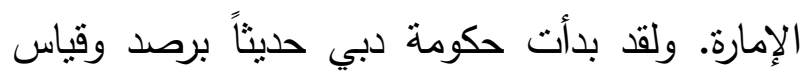
عدد من المؤشرات المتعلقة بالرضا والسعادة للمواطنين عن الخدمات التي تقدمها الإمارة وكذللك قياس مؤشرات الازدهار وإنتاجية المدينة وهذه من القضايا الرئيسية الحديثة التي يركز عليها برنامج الأمم المتحدة للمستوطنات البشرية[ [؟r]

أما آلية تبادل المعلومات بين الجهات الحكومية والخاصة ذات العلاقة بتوفير البيانات

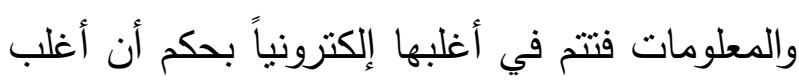

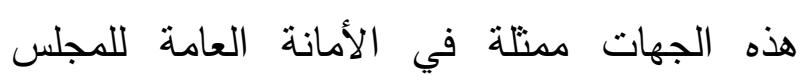
التفيذي لإمارة دبي.

$$
\text { م-r التجارب العالمية }
$$

يتتاول هذا الجزء استعراضاً لبعض التجارب العالمية التي لها السبق والمتميزة في مجال إنشاء وتتغيل وإدارة المراصد الحضرية الوطنية والمحلية واسنتباط المؤشرات الحضرية والقريبة من تجربة المملكة العربية السعودية والتي يمكن أن بستفاد منها في تطوير وتحسين المراصد الحضرية في المملكة وفيما يلي عرض لبعض هذه التجارب: 0- - - تجربة مدينة فانكوفر (كندا)

يعتبر المرصد الحضري بمدينة فانكوفر بمقاطعة برينش كولمبيا من أقدم وأفضل المراصد بدينة فاكرئ 
سيمون فريزر يعمل به عدد محدد من الطلاب المهتمين بالكلية ورئيسة المرصد وهي أكاديمية متخصصة بالدراسات الحضرية. ويعزى سبب عدم استذامة المرصد لارتباطه التتظيمي بالجامعة وهي جهة بحثية استثارية، إذ لا يوجد لديها أي سلطة تتفيذية أو قدرة على اتخاذ القرار ووضع السياسات والخطط للتتمية الحضرية في المدينة[؟ّ]. o-r-r تجربة مدينة تورنتو (كندا)

بدأ المرصد الحضري بمدينة تورنتو بمقاطعة أونتاريوا بكندا في عام ع . .بم وكانت البداية متواضعة وبجهود ذاتية بسيطة من فريق عمل مصغر في جامعة تورنتو عمل على جمع بعض البيانات والمعلومات الأساسية التي تقيس مستوى التتمية في المقاطعة. تلا ذلك تشكيل إدارة صغيرة بجامعة تورنتو بمسمى إدارة المرصد الحضري لمدينة تورنتو تعمل على جمع البيانات والمعلومات لقياس مستوى التقدم في توفير الخدمات وتحقيق الرفاه الاجتماعي للمواطنين. تطور عمل المرصد وبدعم من حاكم ولاية أونتاريوا، وتطور عمل المرصد وتوسع وزاد عدد المؤشرات التي يجمعها عن كامل المقاطعة التي بها عدد من المحافظات وليس فقط مدينة تورنتو، وتحولت إدارة المرصد الحضري إلى معهد لبيانات المدن يرتبط به أكثر من حول العالم ويجمع مؤشرات متقق عليها بين هذه المدن بهدف المقارنة وتبادل الخبرات. وفي عام
وعملت هذه الإدارة على جمع وتحليل البيانات والمعلومات عن البيئة الحضرية والسكان في مقاطعة بربتش كولمبيا وذلك بهدف قياس مستوى الرفاه وتحسين مستوى المعيشة لسكان المدن في المقاطعة. كان التركيز في بداية عمل المرصد على مؤشرات المأوى المناسب، ثم بعد ذلك تطورت لتشمل مؤشرات متعلقة بالبيئة والنقل والنقل العام وممرات المشاة وركوب الدراجات ومستوى البنية التحتية .... إلخ. بقي المرصد نشطاً ونموذجاً يحتذى به في عملية الرصد وجمع وتحليل البيانات والمعلومات وإنتاج المؤشرات وفق منهجية علمية دقيقة بحكم أن العاملين في المرصد هم هن المتخصصين والمهتمين. كما يرتبط بهذا المرصد وب بلديةً في المقاطعة وعدد من المراصد الحضرية العالمية بهدف مقارنة المؤشرات بين هذه المدن وقياس مستوى التقدم وتبادل المعلومات والخبرات في معالجة المشكلات المتعلقة بالبيئة الحضرية. ومع مرور الوقت بدأ الاهتمام والدعم المالي والمؤسسي بالمرصد من قبل الجهات الحكومية وأصحاب المصالح من مؤسسات المجتمع المدني ينلاشى، وكذلك التعاون في توفير البيانات والمعلومات المطلوبة في الوقت المحدد، وكذلك عدم الأخذ بنتائج المؤشرات التي تم رصدها. كل ذللك أسهم في ضعف وتلاشي دور المرصد إلى أن أصبح المرصد الآن إدارة صغيرة بكلية الدراسات الحضرية بجامعة 
في المملكة، وكذلك يوجد هناك عدد من المراصد الحضرية التي تم إنثاؤها حديثاً في الأمانات والبلديات والحكومات المحلية ويعمل كل مرصد على حدة بدون أبي جهاز مركزي منظم لنشاطه ويضع المؤشرات التي يراها مناسبة له، ويرصد ما يتوفر له له من معلومات كما هو الحال في وضع المراصد الحضرية في المملكة العربية السعودية، مع الفارق في أن المراصد الحضرية في دولة المكسيك تدار وتتغل من خلال الجهود الذاتية للعاملين بالجهاز الحكومي أو البلدي نفسه، في حين أن المراصد الحضرية في المملكة تدار وتتغل من خلال عقود استشارية [بr].

ومن أمتلة المراصد الحضرية المحلية في دولة المكسيك المرصد الحضري بمدينة كيهيمي وهو مرصد حضري حديث تم إنشاؤه من قبل الحكومة المحلية بالمقاطعة ويشرف هذا المرصد على جميع الخدمات التي تقدمها البلدية وينتج هذا المرصد عدداً من المؤشرات لقياس أداء البلدية في مستوى تقديم هذه الخدمات ومن ثم الاستفادة من هذه المؤشرات في وضع السياسات والخطط للتنمية الحضرية في المدينة. يقع المرصد الحضري في البلدية المحلية

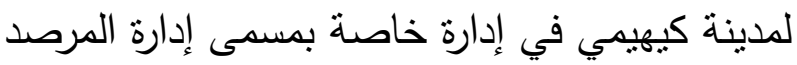
الحضري، وينتج هذا المرصد عدداً من المؤشرات الحضرية ويحصل المرصد على بيانته من الجهات المحلية المعنية بتوفير هذه البيانات والمعلومات ولا
ـ ا ـ ب في أثناء انعقاد المؤتمر الدولي الأول لبيانات المدن بمدينة تورنتو تم تدشين المجلس العالمي لبيانات المدن ليحل محل معهد بيانات المدن، والذي

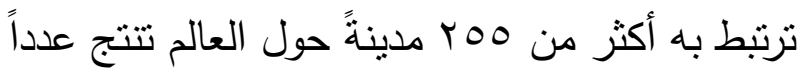

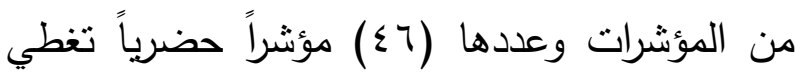
أغلب المحاور الرئيسية المتعلقة بالتتمية الحضرية وفق معايير الأيزو ويتم المقارنة وتبادل المعلومات وتحديثها بين هذه المدن وفق إطار زمني محدد. وتتم عملية تبادل البيانات والمعلومات بين هذه المدن من خلال شبكة تقنية متطورة تمكن كل مدينة عضو في هذا المجلس الاطلاع على نتائج المؤشرات للمدن الأخرى، وكذلك الاطلاع على آلية تحديد القضايا الرئيسية للتتمية الحضرية في المدينة، وكذلك السياسات التي تم اتباعها للتعامل مع هذه القضايا. ولا زال هذا المجلس أحد أنشط الجهات المعنية بالرصد الحضري وتبادل الخبرات وتطوير القدرات المتعلقة بالرصد الحضري على المستوى العالمي. ويعزى نجاح هذا المجلس إلى توفر الدعم المؤسسي والمالي من قبل الحكومة المحلية للمقاطعة وترؤس حاكم مقاطعة أونتاريوا لهذا المجلس [مّأ. - م-r-r التجرية المكسيكية تجربة دولة المكسيك مشابه إلى حد ما لتجربة المملكة إذ يوجد في دولة المكسيك جهاز وطني يعني بجمع وتحليل البيانات والمعلومات على لئ لئل المستوى الوطني مثله مثل العيئة العامة للإحصاء 
البشرية، ويهدف المرصد الحضري إلى إبراز التفاوت والتباين في الموارد الحضرية في اليابان من خلادئه ثلاثة محاور أساسية، وهي البحث والتطوير ، التعليم والتدريب، السياسات وبرامج التتمية، وعليه فقد نم تحديد ثلاث وظائف أساسية للمرصد الحضري الوطني وهي:

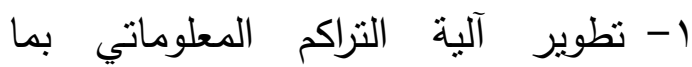
يتضمنه ذلك من جمع وتحليل البيانات ووضعها في لئروني شكل حزم، بالإضافة إلى نشر المعلومات.

r- دعم البحوث والمواد التدربيية من خلال تتظيم دورات تدريبية وندوات ومؤتمرات. ب- تسهيل أنشطة التعليم والتطوير المعرفي

$$
\text { بهذف بناء القدرات البشرية. }
$$

بادر المرصد الحضري الياباني الوطني بأنشطة تهدف إلى إلقاء الضوء على قضايا ومشاكل المناطق الحضرية، وتضمن ذلك تعريف التحديات الرئيسية التي تواجه المناطق الحضرية باليابان، كما تم تطوير سلسلة من الأدوات والإستراتيجيات التي لتربه يمكن أن تستخدم في تحليل الموقف المحلي وتطوير حلول ابتكارية للمشكلات، كما تم أيضاً دعم عمليات صنع القرار والموارد الضرورية لتسهيل تلك العملية. وفي سبيل تحقيق أهدافه طور المرصد الحضري الياباني الوطني سلسلة من المؤشرات التي لفي لهني

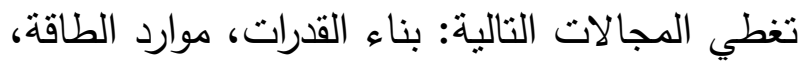

يوجد أي مشكلة في الحصول على المعلومات بحكم أن رئيس البلدية هو الحاكم الإداري المحلي في المدينة ويشرف على جميع الخدمات في المدينة. ويتم تبادل البيانات والمعلومات بشكل آلي بين

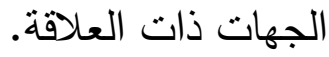

كما يوجد المرصد الحضري للحكومة الإقليمية لمقاطعة غوادالاخارا، وهذا المرصد هو هو مرصد إقليمي على مستوى المقاطعة أو المنطقة ويرصد

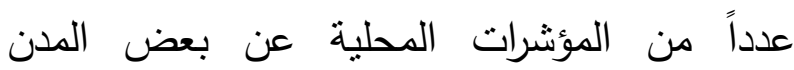
الصغيرة في المقاطعة وبعض المؤشرات الإقليمية المتعلقة بالتتمية الإقليمية في المقاطعة. ويرأس المرصد الحضري مجلس على مستوى المقاطعة

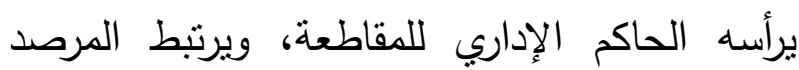

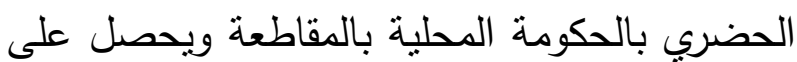

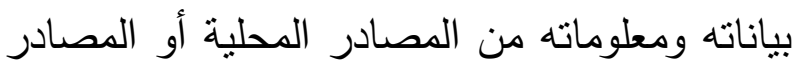
الوطنية للمعلومات [rv].

ويهدف هذا المرصد إلى تطوير وتتمية البيئات الحضرية في المقاطعة ويرتبط هذا المرصد بشبكة المراصد العالمية وينتج عدداً من المؤشرات المتوافقة مع المعايير العالمية. 0-r-r التجربة اليابانية يعد المرصد الحضري الياباني الوطني حديثاً وهو جزء من شبكة المراصد الحضرية العالمية والذي لهي تم بمبادرة من مركز الأمم المتحدة للمستوطنات 
كما قام المرصد بعقد العديد من الندوات وورش العمل في مجالات التتمية الحضرية حضرها العديد من شركاء التتمية. وتتضمن أنشطة المرصد أربعة مجالات رئيسية: - منركاء 1- مجموعة الأنشطة الاقتصادية.

$$
\text { r- مجموعة إصدار الكتب والوثائق. }
$$

r- مجموعة تقديم الدعم الكامل للاراسات والبحوث والدعم الفني وبناء القدرات. ع - مجموعة تقييم أداء الخدمات العامة.

ويتضمن الهيكل التنظيمي للمرصد الحضري،

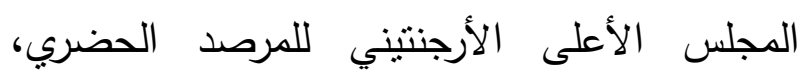
والعاملين بالمرصد والمشروعات المدرجة بخطة الارتيني المرصد، وبعض الاستشاريين [־َّ]

ويرى بعض المختصين أن هذه التجربة للمرصد الحضري الوطني الأرجنتيني التي ترأس فيها

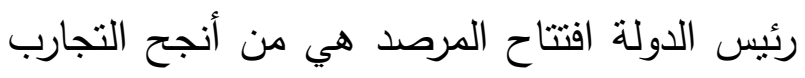
الحديثة في إنثاء المراصد الحضرية الوطنية وذلك لتوفر الدعم السياسي والمؤسسي والمالي

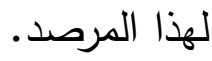

النقل المستدام، الحكم المحلي الحضري، تقييم الآثار البيئية، الأجندة المحلية للقرن الواحد والعشرين،

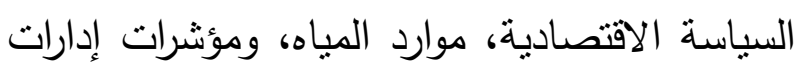

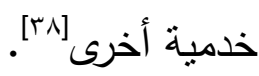
o-r-o تم إنشاء المرصد الحضري الوطني بالأرجنتين

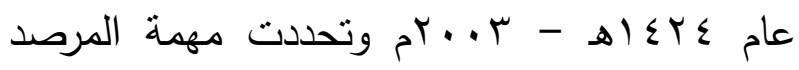
كمركز للأفكار الإبداعية والحلول الذكية وتحليل وتقييم وفهم المؤشرات الحضرية في الدولة، وترأس رئيس الدولة افتتاح المرصد عند بداية تشغيله، وتضمنت خطة عمل المرصد أربعة برامج رئيسية تتركز على التتمية الاقتصادية والاجتماعية ، التتمية

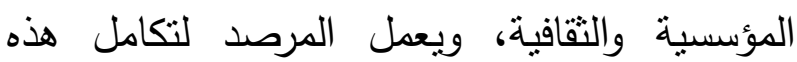
البرامج معاً، ويقوم المرصد بتدريب الطلاب في ولئي عمليات جمع البيانات لقياس رضا المواطنين عن لئن الخدمات المقدمة، وقام المرصد بإنشاء موقع مزدوج

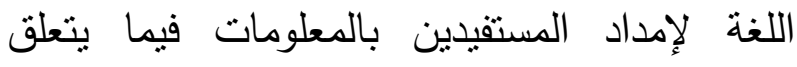
بالتتمية الحضرية في الأرجنتين. ويشارك في تمويل برامج عمل المرصد مؤسسة فورد وبعض المانحين من القطاع الخاص، 
جدول ا ـ الارتباط التظيمي ومستوى التثغيل وعدد المؤشرات الحضرية وآلية جمع وتحليل البيانات وتبادل المعلومات والخبرات للتجارب العالمية مقارنة بتجرية المملكة العربية السعودية.

\begin{tabular}{|c|c|c|c|c|c|c|c|c|c|c|c|c|c|}
\hline \multicolumn{2}{|c|}{ والمعلومات } & \multicolumn{2}{|c|}{ آلية تحليل } & \multicolumn{2}{|c|}{ آلية جمع } & \multicolumn{2}{|c|}{ المؤشرات } & \multicolumn{3}{|c|}{ مستوى التشغيل } & \multicolumn{2}{|c|}{ الارتباط التنظيمي } & \multirow{2}{*}{ /الدنصر } \\
\hline 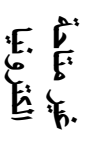 & $\begin{array}{l}E \cdot E \\
E \\
E \\
E \\
E\end{array}$ & 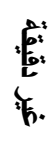 & 㛑: & 管" & 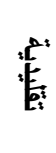 & $\begin{array}{l}\frac{5}{5} \\
6.5\end{array}$ & ह & q & 整 & f: & $\frac{k}{5}$ & $\sum_{\text {हैं }}^{6}$ & \\
\hline \multicolumn{14}{|c|}{ التجارب العربية } \\
\hline$\sqrt{ }$ & & & $\sqrt{ }$ & & $\sqrt{ }$ & & $\sqrt{ }$ & $\sqrt{ }$ & $\sqrt{ }$ & & $\sqrt{ }$ & & السعودية المبية \\
\hline$\sqrt{ }$ & & $\sqrt{ }$ & & & $\sqrt{ }$ & $\sqrt{ }$ & . & $\sqrt{ }$ & $\sqrt{ }$ & $\sqrt{ }$ & $\sqrt{ }$ & $\sqrt{ }$ & مصر \\
\hline$\sqrt{ }$ & & $\sqrt{ }$ & & & $\sqrt{ }$ & & $\sqrt{ }$ & & $\sqrt{ }$ & $\sqrt{ }$ & $\sqrt{ }$ & $\sqrt{ }$ & الأردنن \\
\hline$\sqrt{ }$ & & $\sqrt{ }$ & & & $\sqrt{ }$ & $\sqrt{ }$ & & & $\sqrt{ }$ & $\sqrt{ }$ & $\sqrt{ }$ & $\sqrt{ }$ & البحرين \\
\hline & $\sqrt{ }$ & & $\sqrt{ }$ & $\sqrt{ }$ & & & $\sqrt{ }$ & & $\sqrt{ }$ & & $\sqrt{ }$ & & إمارة دبي \\
\hline \multicolumn{14}{|c|}{ التجارب العالمية } \\
\hline & $\sqrt{ }$ & & $\sqrt{ }$ & $\sqrt{ }$ & & & $\sqrt{ }$ & $\sqrt{ }$ & $\sqrt{ }$ & & $\sqrt{ }$ & & كندانتو \\
\hline & $\sqrt{ }$ & & $\sqrt{ }$ & $\sqrt{ }$ & & & $\sqrt{ }$ & $\sqrt{ }$ & $\sqrt{ }$ & & $\sqrt{ }$ & & فنكوفر - فندا \\
\hline & $\sqrt{ }$ & & $\sqrt{ }$ & $\sqrt{ }$ & & $\sqrt{ }$ & & $\sqrt{ }$ & $\sqrt{ }$ & & $\sqrt{ }$ & & المكسيك \\
\hline & $\sqrt{ }$ & & $\sqrt{ }$ & $\sqrt{ }$ & & & $\sqrt{ }$ & & & $\sqrt{ }$ & & $\sqrt{ }$ & اليابان \\
\hline & $\sqrt{ }$ & & $\sqrt{ }$ & $\sqrt{ }$ & & $\sqrt{ }$ & & & & $\sqrt{ }$ & & $\sqrt{ }$ & الارجنتين \\
\hline
\end{tabular}

منها من يرتبط ببعض الجهات الأكاديمية أو الجهات الخاصة وتكون معظم هذه المراصد محلية وإقليمية مستقلة ومرتبطة مباشرةً بالمرصد الحضري العالمي بمدينة نيروبي بكينيا، أما تجربة المملكة لقد تم إنشاء وتتغيل معظم المراصد الحضرية من خلال التعاقد مع مكاتب اسنتارية متخصصة، وبعضها تم بالتعاون مع المرصد الحضري العالمي وبعض
يتضح من جدول المقارنة رقم (1) ما يلي: أولاً: تختلف جهة الارنباط للمراصد الحضرية من دولة إلى أخرى - وفي تجارب معظم الدول العربية ترتبط المراصد بالوزارات والجهات المركزبة المعنية بالتخطيط والتطوبر الحضري للمدن، في حين أن تجارب المراصد الحضرية في بعض الدول العالمية ترتبط المراصد الحضرية بجهات مختلفة 
العربية السعودية التي ترصد المؤشرات الحضرية المتفق عليها عالمياً وعددها (10) مؤشراً حضرياً بالإضافة إلى عدد من المؤشرات الإضافية الخاصة بكل مدينة أو منطقة.

رابعاً: آلية جمع البيانات والمعلومات تتبع الطرق التقليدية من خلال ضوابط الاتصال والتقارير والإحصاءات الدورية في أغلب المراصد الحضرية في الدول العربية باستثناء المرصد الحضري لإمارة

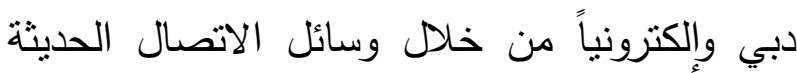
وتطبيق التقنيات الحديثة في أغلب المراصد

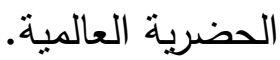

خامساً: تبادل المعلومات ومقارنة المؤشرات في أغلب المراصد الحضرية في الدول المتقدمة تتم آلياً ومتاحة من خلال شبكات تقنيات المعلومات الحديثة، أما عملية تبادل المعلومات ومقارنة المؤشرات في معظم المراصد الحضرية في الدول العربية، وكذلك في تجربة المملكة العربية السعودية تتم بالطرق التقليدية وعملية الحصول عليها صعبة من خلال ضباط الاتصال والمراسلات مع الجهات المعنية وهي غير متاحة إلكترونياً.

سادساً: تختلف قوة المرصد الحضري في عملية دعم القرار من دولة إلى أخرى ومن مدينة إلى

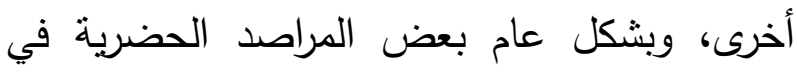
بعض الدول المتقدمة تعمل بشكل فعال في عملية دعم القرار المحلي وتوجيه الخطط والسياسات التتموية في البيئات الحضرية، أما تجربة معظم
المنظمات الإقليمية المتخصصة التابعة لبرنامج UN ) الأمم المتحدة للمستوطنات البشرية HABITAT)، والمعهذ العربي لإنماء المدن وكمثال على ذلك المرصد الحضري لأمانة منطقة المدينة

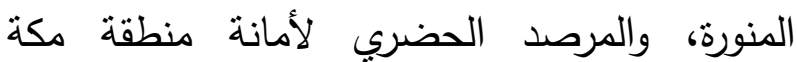
المكرمة، والمرصد الحضري لأمانة محافظة جدة وتعد هذه المراصد الحضرية منميزة وحصلت على بعض الجوائز العالمية في مجال الرصد الحضري وإنتاج المؤشرات الحضرية.

ثانياً: إن مستوى التتغيل للمراصد الحضرية يختلف من دولة إلى أخرى بعضها أنشأ مراصد حضرية على جميع المستويات المحلي والإقليمي والوطني، والبعض الآخر أنثأ مراصد حضرية على جلى المستوى المحلى والإقليمي، أو المستوى الإقليمي أو الو المستوى الوطني، في حين أن تجربة المملكة نثير الإني

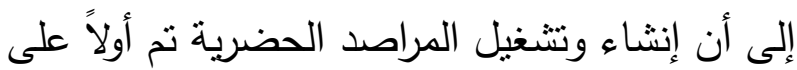
المستوى المحلي والإقليمي، وحديثاً تم إنشاء المرصد إثناء الحضري الوطني. ثالثاً: تختلف الاهتمامات في عملية الرصد واستتباط المؤشرات الحضرية التي يرصدها كل مرصد من مرصد إلى آخر وحسب مستوى وخصوصية كل مدينة ومنطقة، لكن بشكل عام تعمل أغلب المراصد الحضرية على عدد محدد من

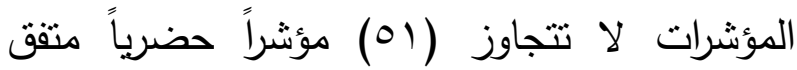
عليها عالمياً أما المراصد الحضرية في أغلب الدول العربية، وكذلك تجربة المراصد الحضرية في المملكة 
المتوسطة والصغيرة في المملكة لا تتوافق مع

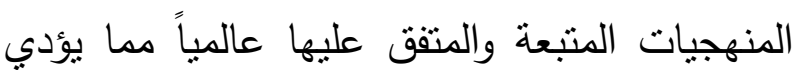

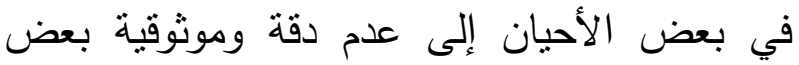

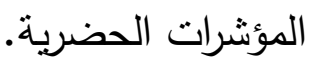

\section{4- النتائج والتوصيات}

سعى هذا البحث إلى تسليط الضوء على واقع المراصد الحضرية في المملكة العربية السعودية والتحديات التي تواجهها وسبل تطويرها، وعقد مقارنة بين تجربة المملكة في إنثاء وتشغيل وإدارة المراصد الحضرية مقارنة بتجارب الدول الأخرى من خلال عرض نظري لمفهوم المراصد الحضرية، والمؤشرات الحضرية، والوضع الراهن للمراصد الحضرية في المملكة العربية السعودية، ومقارنة تجربة المملكة بتجارب الدول الأخرى في مجال إنشاء وتتشغيل وإدارة المراصد الحضرية، والمؤشرات الحضرية، وآلية جمع وتحليل البيانات والمعلومات وقد دلت النتائج على ما يلي: ولحع

\section{1 - 1 ملخص لأهم نتائج البحث}

أولاً: موضوع المراصد الحضرية داخل المدن هو موضوع حديث على المستوبين العالمي والمحلي ولقد عملت بعض المدن والأقاليم والدول في إنشاء وتشغيل المراصد الحضرية للخروج بمؤشرات حضرية تسهم في دعم القرار المحلي وتوجيه السياسات والخطط والبرامج لتحقيق التتمية الحضرية المستدامة في البيئات الحضرية بعد مؤتمر (الموئل) الأول
المراصد الحضرية في الدول العربية، وكذلك في تجربة المراصد الحضرية في المملكة ما زالت المراصد الحضرية ضعيفة وغير مؤثرة بشكل كبير في عملية دعم القرار المحلي وفي توجيه الخطط والسياسات التتموية في المدينة بإستثناء المرصد الحضري لإمارة دبي التي يعتبر المرصد الحضري

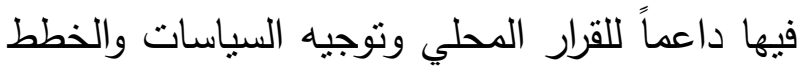
التنموية في الإمارة.

سابعاً: تختلف التحديات التي تواجهها المراصد الحضرية من مرصد إلى آخر، وفي تجربة

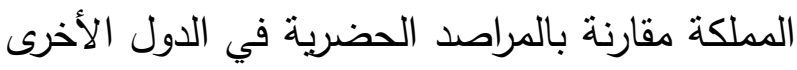
يوجد هناك تحديات متعلقة بعدم توفر البيانات

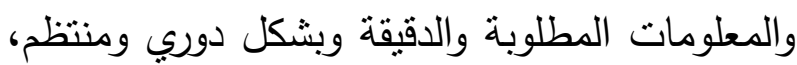
مما يؤثر على استتباط المؤشرات في بعض من هذه المراصد الحضرية، وكذللك ضعف التتسيق وعدم تعاون بعض الجهات في توفير المعلومات المطلوبة

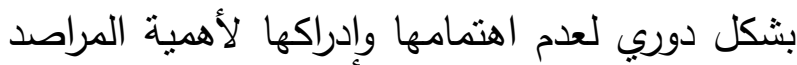
الحضرية في عملية دعم القرار وتوجيه الخطط والسياسات التتموية، كما تعاني معظم هذه المراصد من ضعف الموارد البشرية المتخصصة، وتدني الميزانيات المخصصة والدعم المالي، وضعف تطبيق النقنيات الحديثة في عملية تبادل المعلومات والخبرات وهذا نتيجة لحداثة هذه التجربة في بعض هذه المراصد، كما أن أسلوب تحليل البيانات والمعلومات في بعض المراصد الحضرية التي تم إنشاؤها حديثاً في بعض أمانات وبلديات المدن 
الحضرية الخاصة بكل مدينة أو إقليم والتي تعكس خصوصية هذه المدينة أو الإقليم.

خامساً: علية جمع المعلومات للمراصد الحضرية في الكثير من الدول المتقدمة نتم إلكترونياً من خلا شبكات تقنيات المعلومات الحديثة، في هن حين أن تجربة جمع البيانات والمعلومات في المراصد الحضرية في المملكة العربية السعودية وبعض الدول العربية التي أنشأت المراصد الحضرية في بعض المدن والأقاليم في عملية جمع البيانات والمعلومات تتم بالطرق التقليدية أما من خلال المخاطبات الرسمية مع الجهات الحكومية أو بطون الخاصة ذات العلاقة أو من خلال التقارير الدورية التي تتشرها هذه الجهات أو المسح الميداني في حالة عدم توفرها.

سادساً: المؤشرات الحضرية متاحة إلكترونياً لجميع الثركاء في معظم المراصد الحضرية في المدن في الدول المتقدمة بهدف الاستفادة من تجارب

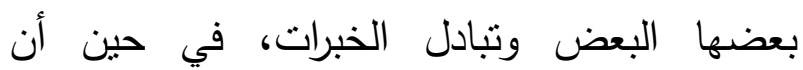
المؤشرات الحضرية في أغلب المراصد الحضرية في المملكة وفي معظم المراصد الحضرية في الدول العربية غير متاحة إلكترونياً، ومن ثم يصعب مقارنة

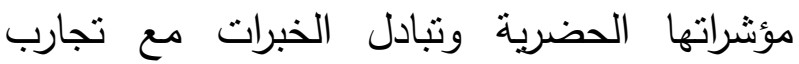
المراصد الحضرية في الدول الأخرى.

سابعاً: قوة وتأثنير المرصد الحضري في دعم

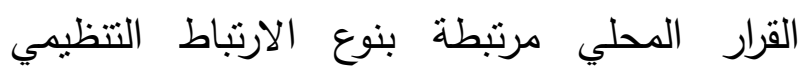
للمرصد، وكلما ارتبط المرصد الحضري بجهة قوية لاية العرباطي
بمدينة فانكوفر - بكندا ومؤتتر الموئل الثاني بمدينة إسطنبول - بتركيا وبدعم من مركز الأمم المتحدة

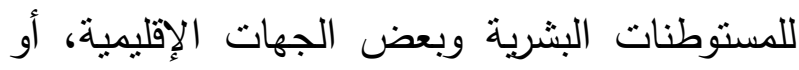
بعض الجهات المحلية الأكاديمية أو مؤسسات المجتمع المدني في هذه الدول.

ثانياً: أصبحت المراصد الحضرية ضرورة للتعامل مع عملية التحضر السريعة داخل المدن وتتامي المشكلات الحضرية وقلة الموارد المالية والبشرية مما حتم على متخذي القرار المحلي الترشيد وتوجيه الموارد بما يخدم التتمية الحضرية المستدامة. ثالثاً: تختلف تجربة كل دولة عن تجارب الدول الأخرى في عملية إنشاء وتشغيل المراصد

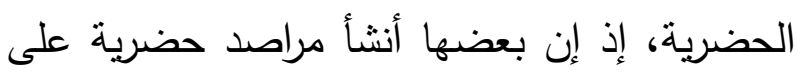
المستوى المحلي والإقليمي، والبعض الآخر أنشأ مراصد حضرية على المستوى الوطني، وتتمنل تجربة المملكة في إنشاء وتشغيل المراصد الحضرية في أن معظم المراصد الحضرية هي مراصد حضرية

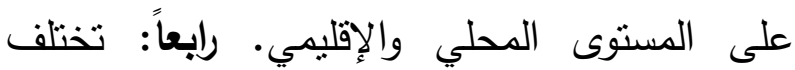
المراصد الحضرية في عملية الرصد وإستتباط المؤشرات الحضرية ويختلف عدد المؤشرات الحضرية التي يتم رصدها في المرصد الحضري من دولة إلى أخرى، لكن تتفق معظم المراصد الحضرية

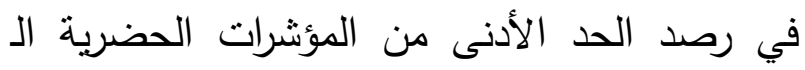

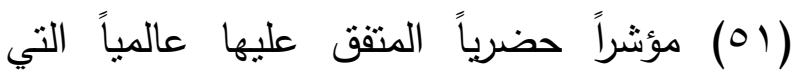
ترصدها أغلب المراصد الحضرية في الكثير من عن عنديا المدن العالمية، يضاف لها بعض المؤشرات 
والبرامج ودعم القرار المحلي ومن ثم تحقيق التتمية

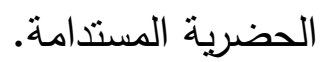

ثاني عشر: ضعف الميزانيات والموارد المالية

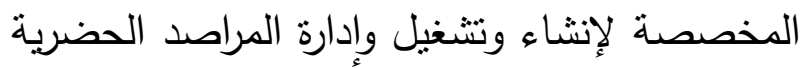

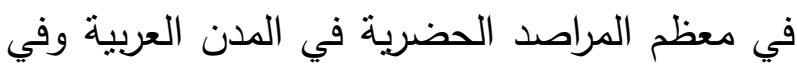
المراصد الحضرية في المملكة مما يؤثز بشكل كبير على ديمومة واستمرارية عمل هذه المراصد.

رابع عشر: عملية نوطين الموارد البشرية العاملة في المراصد الحضرية في المملكة ضعيفة جداً وبالأخص الموارد البشرية المتخصصة فنباً في عمل المرصد الحضري إذ إن تجربة إنثاء وتنشغيل وإدارة معظم المراصد الحضرية في المملكة تتم بعقود مدتها سنتين تتفذ من قبل مكاتب استشارية

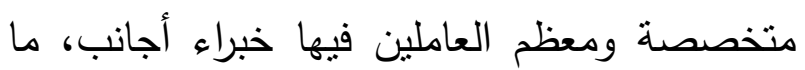
عدا رئيس المرصد الحضري وبعض المساعدين الإداريين له.

\section{r r r r r توصيات البحث}

في ضوء أبرز النتائج التي توصل إليها البحث، يقام الباحث مجموعة من التوصيات أهمها: 1- أهمية الاستمرار في إنشاء وتتشيل المراصد الحضرية المحلية والإقليمية في كافة المدن والاقاليم في المملكة العربية السعودية ودعم ومساندة المراصد الحضرية القائمة منها لما لها من دور فئه رئيسي في عملية دعم القرار المحلي وتوجيه الخطط
ومؤثرة في الجهاز كلما كان المرصد الحضري أكثر

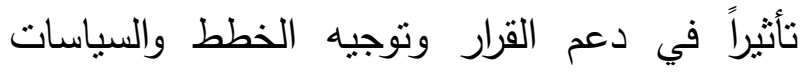
التنموية في البيئات الحضرية. ثامناً: آلية وأساليب تحليل والمعلومات للخروج بالمؤشرات الحضرية في بعض المراصد الحضرية وبالأخص في المراصد الحضرية التي تم إنشاؤها حديثاً في المدن الصغيرة والمتوسطة

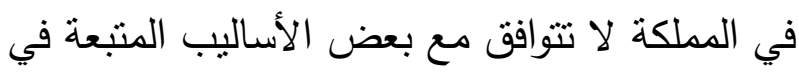

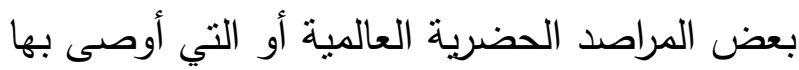
المرصد الحضري العالمي بمدينة نيروبي بكينيا التابع لبرنامج الأمم المتحدة للمستوطنات البشرية (UNHABITAT) وموثوقية بعض المؤشرات الحضرية المستتبطة. تاسعاً: صعوبة الحصول على بعض البيانات

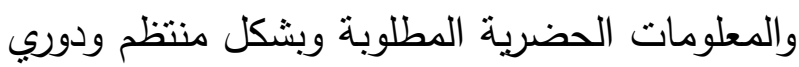
مما يؤثر سلباً على عملية خروج المؤشرات الحضرية في الوقت المطلوب والمحدد لها. عاشراً: تعاني معظم المراصد الحضرية في المملكة من ضعف الموارد البشرية الوطنية المؤهلة والمتخصصة فنياً مقارنة ببعض المراصد الحضرية في بعض المدن العالمية. حادي عشر: ضعف إدراك واهتمام بعض المسئولين في بعض الأمانات والبلديات بأهمية المراصد الحضرية في توجيه السياسات والخطط 
المملكة العربية السعودية وتفعيل دورها لكي تصبح أداة لدعم القرار المحلي وتوجيه الخطط والسياسات التتموية في البيئات الحضرية وتحقيق التتمية

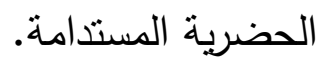

- V أهمية توظيف وسائل الثقنية الحديثة للمراصد الحضرية القائمة في المملكة العربية السعودية في عملية جمع وتصنيف وتحليل المعلومات للخروج بمؤشرات حضرية دقيقة وموثوقة تسهم في دعم القرار المحلي.

- أهمية التنسيق والتعاون مع المسئولين في بعض الجهات الحكومية والخاصة ومؤسسات المجتمع المدني المعنية بتوفير البيانات والمعلومات الدقيقة وفي الوقت المحدد لها وبشكل دوري للمراصد

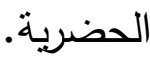

9- ضرورة ربط جميع المراصد الحضرية المحلية والإقليمية القائمة في المملكة بشبكة تقنيات متطورة ترتبط بالمرصد الحضري الوطني الذي تم إنشاؤه حديثاً والمرصد الحضري العالمي والمراصد الحضرية العالمية والإقليمية الأخرى بهرف المقارنة وتبادل الخبرات في التعامل مع القضايا الحضرية

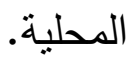

•

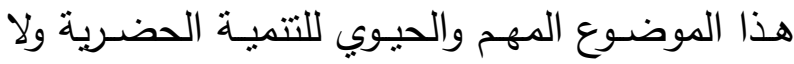
سبما البحوث المتعلقة بقياس مدى استفادة المدن والأقاليم من المراصد الحضرية وأثرها في عملية دعم البح
والسياسات التتموية في البيئات الحضرية وتحقيق التتمية الحضرية المستدامة.

r- ضرورة إنشاء وحدات تتظيمية وإدارية ثابته ومستقلة بمستوى إدارة عامة بمسمى الإدارة العامة للمرصد الحضري ضمن الهيكل التتظيمي لإلهي للجهاز البلدي وداعمة للقرار في البيئة الحضرية، ترتبط مباشرة بأعلى سلطة في الجهاز البلدي. r- أهمية الاستفادة من المرصد الحضري العالمي والمراكز العالمية المتخصصة في مجال الرصد الحضري والمراكز والهيئات الإقليمية المتخصصة، وبالأخص في عملية تبادل الخبرات في عملية جمع وتصنيف وتحليل البيانات والمعلومات للخروج بالمؤشرات الحضرية الدقيقة

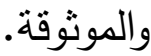

ـ- أهمية تثغيل وتفعيل دور المرصد الحضري الوطني في المملكة العربية السعودية الذي نم إنشاؤه حديثاً لكي يكون ذراعاً داعماً في عملية إنثاء ونتغيل وإدارة المراصد الحضرية المحلية والإقليمية في المملكة، وتقديم الدعم والمشورة والمساندة لها.

0- ضرورة نوفير الموارد البشرية الوطنية المتخصصة والمؤهلة التأهيل الجيد للمراصد الحضرية القائمة في المدن في المملكة العربية السعودية. 7- أهمية زيادة الدعم المالي ورصد الميزانيات المطلوبة للمراصد الحضرية القائمة في 


$$
\text { السعودية. }
$$

$[\wedge]$

القرار المحلي وتوجيه الخطط والسياسات التنموية في

البيئة الحضرية.

\section{المراجع}

UN HABITAT. (2015) "A guide to Setting up an Urban Observatory" United Nations Human Settlements Programme, Nairobi, Kenya.

Claudio Acioly. (2014) "Indicators for strategic city Planning and Decision-making. International Experiencias, The City Prosperity Index" United Nations Human Settlements Programme, Riyadh, Saudi Arabia.

Tarek, El- Sheikh. (2014) "The Role of the Local Urban Observatory in City Development" UN HABITAT, Riyadh, Saudi Arabia.

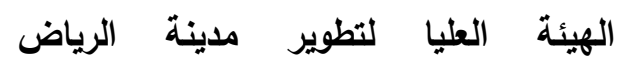

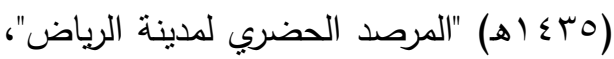
الرياض، المملكة العربية السعودية.

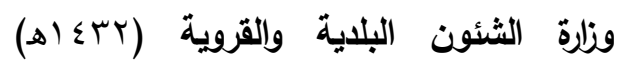

"مشروع المرصد الحضري الوطني" التقرير الفني الثاني، الرياض، المملكة العربية السعودية.

Mboup, Gora. (2014) "The Purpose to Have Urban observatories" paper presented in The First Global Cities Summit, Getting on Track: Sustainable \& Inclusive Prosperity for Cities. May 15-16, 2014. Toronto, Canada.

Tarek, El- Sheikh. (2014) "The City Prosperity Index Notions and Measurements" UN HABITAT, Riyadh, Saudi Arabia.

Newton, Peter, W. (2014) "Urban Indicators and the Management of Cities" Paper presented in The First Global Cities Summit, Getting on Track: Sustainable \& Inclusive Prosperity for Cities. May 15-16, 2014. Toronto, Canada.

$$
\begin{aligned}
& \text { الجطيلي، إبراهيم عبد العزيز (مبـ اهـ) "مشروع } \\
& \text { وزارة الثئون البلدية والقروية للمرصد الحضري } \\
& \text { الوطني" ورقة عمل، مقدة للملتقى الأول للمرصد }
\end{aligned}
$$

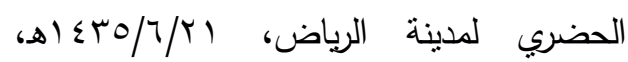

$$
\begin{aligned}
& \text { الرياض، المملكة العربية السعودية. }
\end{aligned}
$$

Fox, Mark, S. (2015) "A foundation Ontology for Global City Indicators" Global Cities Institute, Toronto, ON, Canada.

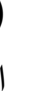

\section{]}$$
\text { صغير، أحمد محمد (•rاء (ه) "تصور للمراصد، }
$$

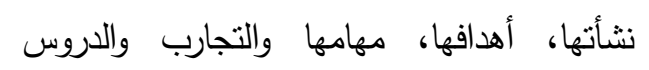

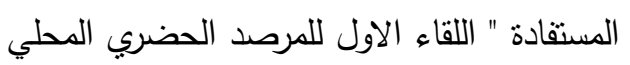$$
\text { لكدينة القنيطرة، مشروع تتشيط الرصد والمتابعة }
$$

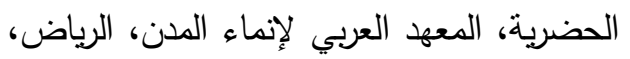

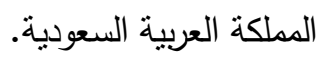

[1]

UN HABITAT. (2009) "Urban Indicators Guidelines, Better Information, Better Cities" United Nations Human Settlements program, Nairobi, Kenya.

Pennachetti, Joe. (2014) "Global Standers for Global Cities" Paper presented in the Global Cities Summit, May 15, 2014. Toronto, Canada.

Mc Carney, Patricia. (2014) "Global Urban Observatories Challenges and opportunities" keynote speech Presented in The First Global Cities Summit, Getting on Track: Sustainable \& Inclusive Prosperity for Cities. May 15-16, 2014. Toronto, Canada.

$$
\begin{aligned}
& \text { صغير، أحمد محمد (•rع اهـ) "مشروع تتشيط } \\
& \text { الرصد الحضري والمتابعة الحضرية للتنمية }
\end{aligned}
$$

المستدامة في المدن العربية" ورقة عمل مقدمة للقاء

الأول للرصد الحضري المحلي لمدينة القنبطرة" المعهد العربي لإنماء المدن، المكنب الاقليمي للمدن العربية بيرنامج الأمم المتحدة للمستوطنات لأنماء

$$
\text { البشربة، الرياض، المملكة العربية السعودية. }
$$

وزارة الشئون البلدية والقروية، (بr؟ (هـ)

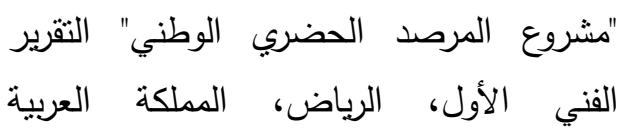


الخلاقي، أحمد (0بعاءه) تجربة المرصد الحضري لمدينة مكة المكرمة" ورقة عمل قدمت في المرصد الحضري لأمانة منطقة مكة المكرمة، مكة المكرمة، المملكة العربية السعودية.

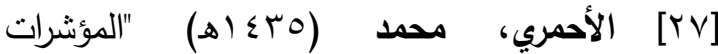
الحضرية لمدينة الرياض لعام عبـأه" ورقة عمل، مقدمة للملتقى الأول للمرصد الحضري

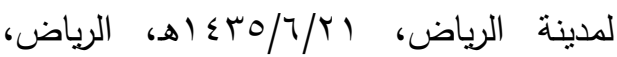

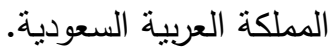

Abdul Rahman, Al Sultan. (2014) "Riyadh Urban Observatory" Paper Presented in the First Global Cities Summit, Getting on Track: Sustainable \& Inclusive Prosperity for Cities. May 15-16, 2014. Toronto, Canada.

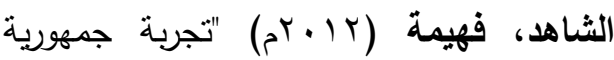
مصر العربية والدول العربية في إنشاء المراصد الحضرية وإعداد المؤشرات الحضرية " ورقة عمل مقدمة في المؤتمر الإقليمي لمنظمة المدن العربية والمعهد العربي بالتعاون مع مكتب الموئل بالكويت، الكويت، الكويت.

الهيئة العامة للتخطيط العمراني (بس؟ اهـ) "تجربة مصر في إنشاء وتشغيل المراصد الحضرية" القاهرة، مصر •

المؤسسة العامة للإسكان والتظوير الحضري

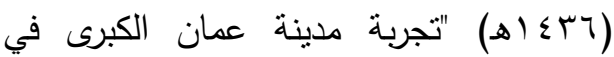
إنشاء المراصد الحضرية" عمان. الأردن.

وزارة شئون البلديات والزراعة (هب؟ اهـ) $[r r]$ "المرصد الحضري في مملكة البحرين" المنامة،

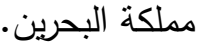
الجلجولي، محمد (ع ا • rم) "المرصد الحضري $[\mathrm{rr}]$ بدبي جهاز لاعم القرار" ورقة عمل مقدمة في

[YT]

$[r \wedge]$

[r.]

[r)]
الهيئة العليا لتطوير مدينة الرياض (0باء اهـ) $[1 \wedge]$ "الررصد الحضري لمدينة الرباض،" الرياض،

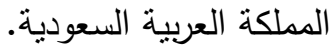

الهيئة العليا لتطوير مدينة الرياض (ع سبا (هـ) "المؤشرات الحضرية لمدينة الرياض" الرياض،

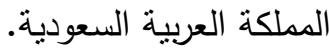

UN HABITAT. (2014) "Monitoring Post 2015 Sustainable development Agenda Targets Sustainable Urbanization in Focus" The Role of Urban Observatory, Arab Urban development Institute, Kuwait 27-29 May 2014.

ونارة الشئون البلاية والقروية، وكالة الوزارة

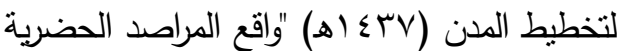
في المملكة" الرياض، المملكة العربية السعودية.

قرار مجلس الوزراء رقم (ع ا-ه/T/د)،

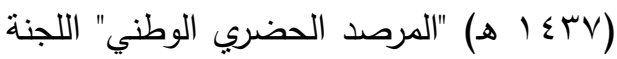
الدائمة لمجلس الثئون الاقتصادية والتتمية، الرياض، المملكة العربية السعودية. مصطفى، أحمد فريد (T (. Trم) "تجربة إنشاء $[\mathrm{rT}]$ وتتغيل المرصد الحضري المحلي للمدينة المنورة الكبرى (رؤية مستقبلية بعين الحاضر )" أمانة منطقة المدينة المنورة، إدارة التتمية الإقليمية، وزارة الثئون البلدية والقروية. الفاروقي، محمد (דبع اهـ) "تجربة المرصد الحضري لمنطقة المدينة المنورة الواقع ... التحديات... التطلعات" ورقة عمل قدمت في المرصد الحضري للمدينة المنورة، أمانة منطقة المدينة المنورة، المملكة العربية السعودية. Al Bar, Osama. (2014) "Makah Urban Observatory" Paper Presented in the First [ro] Global Cities Summit, Getting on Track: Sustainable \& Inclusive Prosperity for Cities. May 15-16, 2014. Toronto, Canada. 


\section{Toronto, Canada.}

Moreno, Eduardo, Lopez. (2014) " urban Observatory: The Mexican Experience" Paper presented in The First Global Cities Summit, Getting on Track: Sustainable \& Inclusive Prosperity for Cities. May 15-16, 2014. Toronto, Canada.

Francisco, Perez. (2014) " Experience in Latin America /CPI as a "tailor applicable" methodology" paper presented in Future Saudi cities Project workshop. December 9-10, 2014. Riyadh. Saudi Arabia.

Japan Urban Observatory. (2015) "The Japan Urban Observatory is part of the Global Urban [个人]

[r] المؤتمر الأول لقمة المدن العالمية، لتحقيق الازدهار المستدام والثامل للمدن. مايوا 10 1-

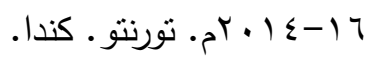

Holden, Meg. (2014) "The Regional Vancouver Urban Observatory (RVU): Counting on Vancouver, Our View of The region" Urban Studies program, Simon Frazer University, Vancouver, Canada.

Mc Carney, Patricia. (2014) " Global Standards for Global Cities: The Changing world of International Standards for Cities" Paper Presented in The First Global Cities Summit, Getting on Track: Sustainable \& Inclusive Prosperity for Cities. May 15-16, 


\section{ملحق رقم (1)}

جدول ا ـ الوضع الراهن لإنشاء وتثغيل وإدارة المراصد الحضرية (الجهة المسئولة، حالة المرصد، نوع الارتباط التنظيمي، مستوى التشغيل، عدد المؤثرات، آلية جمع البيانات، آلية تحليل البيانات، وآلية تبادل البيانات والمعلومات)

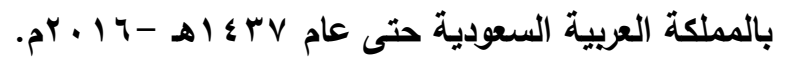

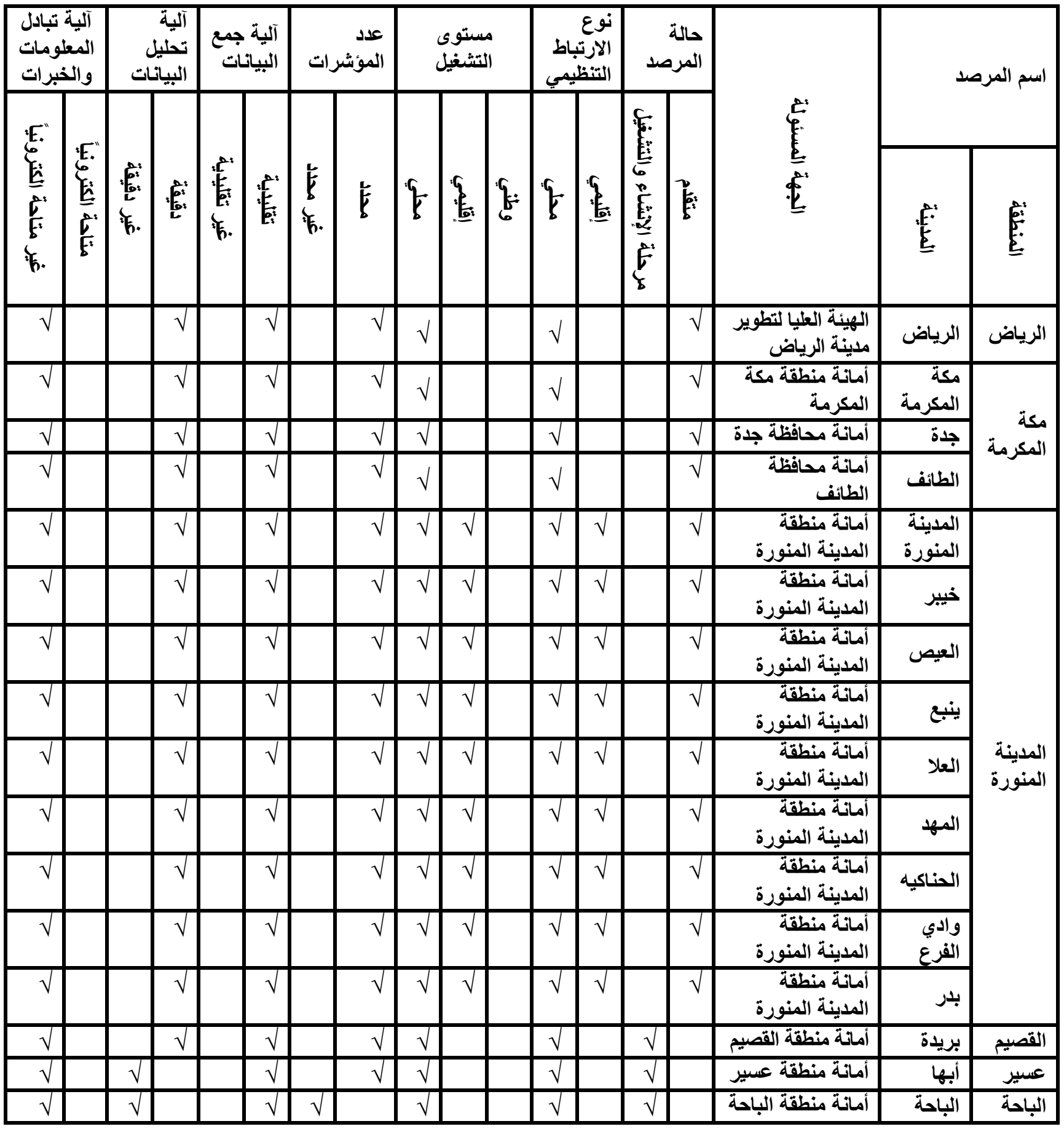




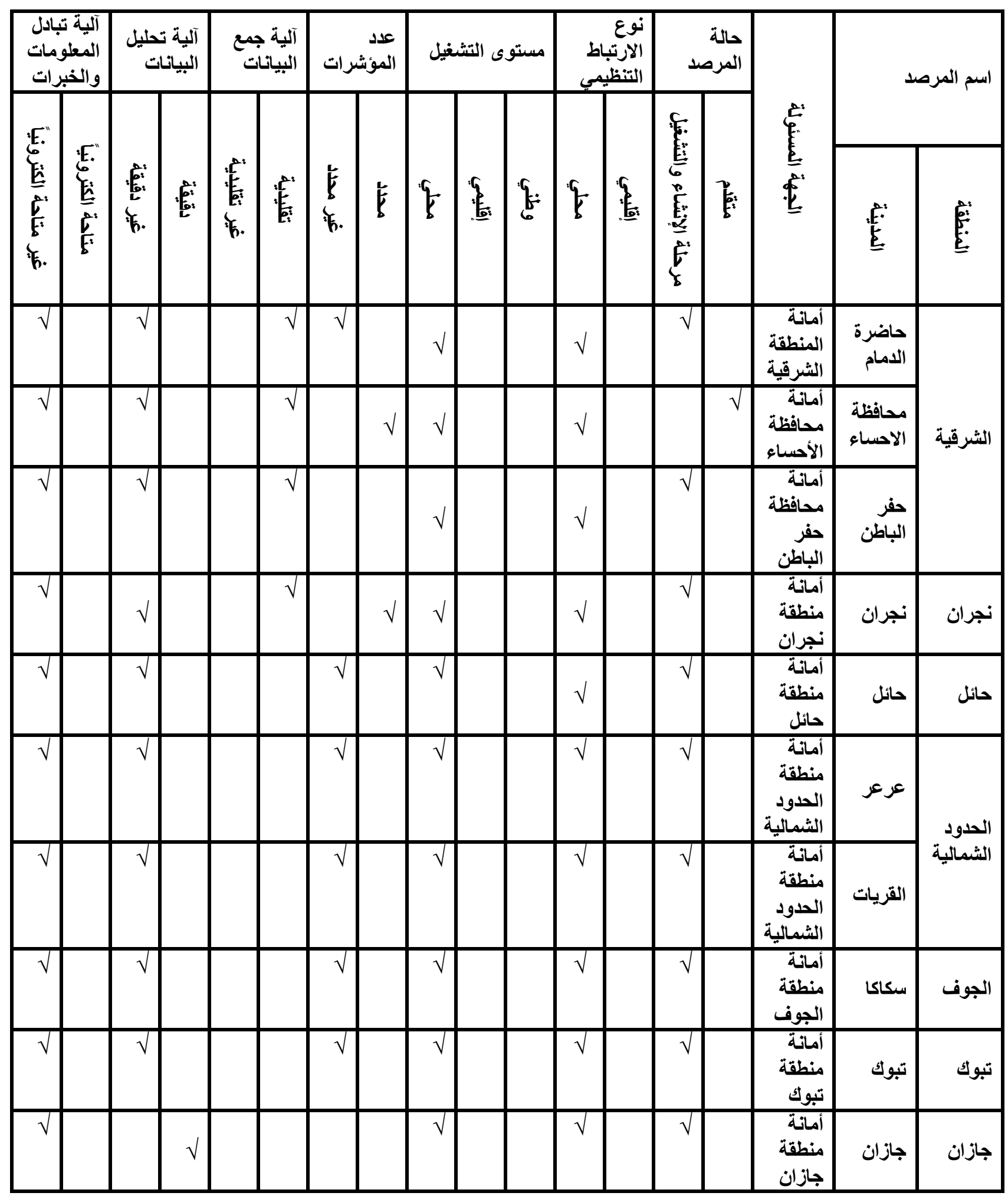

المصدر : الباحث. 


\title{
Urban Observatorys (Comparison of the Experience of the Kingdom of Saudi Arabia with Other Countries) "Challenges and Ways for Improvements"
}

\author{
Ameer Mohammed Al-Alwan \\ Institute of Public Administration, P.O.Box 68638, Riyadh, 11537, Saudi Arabia \\ ameeralalwan@yahoo.com
}

\begin{abstract}
The aim of this research is to study the experience of Saudi Arabia, in establishing, operating, and managing urban observatories, deriving urban indicators, and the mechanism of collecting, classifying, and analyzing data compared to the experiences of other countries. Furthermore, this research will focus on the challenges facing urban observatories and suggest ways to improve its work. The results of this research show that first: urban observatories is a global trend as well as a necessity to dell with rapid urbanization in cities, increased urban problems, and as a tool to support local decision-making and direct resources for sustainable urban development. Second, the experience in establishing and operating, and management of urban observatory is different from country to country and the challenges that it faces. Third, results show The main challenges faces urban observatories in the kingdom are mainly lack of specialized and trained national labor force, weak budgets and financial resources, lack of coordination and cooperation between governments and private agencies responsible for providing data, and weak application of modern technology to facilitate and improve the work of urban observatories in collecting, classifying, analyzing and exchange of data, and deriving urban indictors, and experiences between the different organizations and other urban observatories. Finally, this research recommend that local and regional municipalities in the kingdom must continue to establish and operate urban observatories, and provide it with the necessary specialized and trained national labor force, necessary financial resources and budgets, support it with needed technology, and increase cooperation and coordination between the different stake holders. In addition this research, recommend that the recently established national urban observatory must be activated to provide the necessary support for local and regional urban observatories in the kingdom.
\end{abstract}

Keyword:Urban Observatories, Urban Indicators, UN HABITAT. 